\title{
Stiffness Analysis of Recycled Self-Compacting Concrete-Filled Circular Steel Tubular Columns under Eccentric Compression
}

\author{
Feng Yu, Pengcheng Xu, Yuan Fang $(D$, Yang Zhang, and Junjie Jiang \\ Department of Civil Engineering and Architecture, Anhui University of Technology, Ma'anshan 243032, China \\ Correspondence should be addressed to Yuan Fang; fyuan86@ahut.edu.cn
}

Received 17 April 2019; Accepted 11 June 2019; Published 1 July 2019

Guest Editor: Majid Ali

Copyright (c) 2019 Feng Yu et al. This is an open access article distributed under the Creative Commons Attribution License, which permits unrestricted use, distribution, and reproduction in any medium, provided the original work is properly cited.

\begin{abstract}
In this study, twenty-one recycled self-compacting concrete-filled circular steel tubular (RSCFCST) columns are designed and tested under eccentric compression. The studied parameters including the replacement ratio of the recycled coarse aggregate (RCA), strength grade of concrete, eccentricity, and length-diameter ratio $(L / D)$ of specimens are considered. The load-stiffness curves of the specimens are obtained by observing the whole process of loading, and the effects of various parameters on the stiffness of the specimens are analyzed. Test results demonstrate that the RSCFCST short columns $(L / D \leq 4)$ under eccentric compression exhibit drum-like bending failures, while the RSCFCST long columns $(L / D>4)$ under eccentric compression experience the global flexural buckling failure modes. With the replacement ratio of RCA, the length-diameter ratio or eccentricity increases, and the bearing capacity of specimens under eccentric compression decreases. However, the increase in the strength grade of concrete increases the bearing capacity. The stiffness of the RSCFCST columns under eccentric compression gradually increases as the strength grade of concrete increases, while the eccentricity had an adverse effect on stiffness of specimen. With the increase of load, the increase of the length-diameter ratio would accelerate the stiffness degradation of specimen. The effect of the replacement ratio of RCA on stiffness of specimen in the elastic stage is not obvious. A validated FE model is employed to conduct parametric studies to widen the available test results. Additionally, an analytical model for predicting the effective stiffness of the RSCFCST columns under eccentric compression is proposed based on the moment magnifier method, and verification of this method is performed using the test data and FE analysis.
\end{abstract}

\section{Introduction}

With the rapid renewal and development of the city, a large amount of waste concrete is produced. At present, the majority of these concrete wastes in China is directly landfilled or piled up in open air without any environmental treatment $[1-3]$. The recycling rate is very low. Therefore, how to recycle these wastes reasonably and effectively to reduce land occupancy and environmental pollution has attracted more and more attention.

Vries and Kisku $[4,5]$ demonstrated the feasibility of recycling to deal with these waste concrete. Laserna, Thomas, Shaikh, and Zhu [6-9] carried out the experiments on the mechanical properties and durability of recycled aggregate concrete. Test results indicated that up to $25 \%$ of ordinary coarse aggregates were replaced by RCAs, without significant effect of mechanical properties. In addition, Tam [10] examined three presoaking treatment methods in weakening the mortar attached to RCA. Results revealed that the mechanical properties of recycled aggregate concrete making from these three treatment methods were significantly improved in quality compared with using the traditional methods. In short, these studies confirm the feasibility and reasonability of recycled aggregates in engineering application.

Concrete-filled steel tube (CFST), a composite structure which effectively exerts the mechanical advantages of both the outer steel tube and core concrete, has been widely used in engineering structures. A large number of analytical and experimental investigations on CFST have been conducted, and series of achievements have been made [11-15]. Different from that of the ordinary CFST, the filler of recycled concrete-filled steel tube (RCFST) is recycled aggregate concrete. Mohanraj et al. [16] conducted an experiment on 
the behavior of square and circular RCFST columns subjected to axial compression. The influences of the confinement of concrete, steel tube dimensions, and shapes were examined, and the applicability of the current CFST design provisions for RCFST columns was evaluated. Subsequently, an experimental study on RCFST columns under eccentric compression was proposed by Yang and Han [17] and Chen et al. [18]. Results showed that the failure mode of RCFST columns under an eccentric load was overall buckling, which was similar to that of the ordinary CFST columns. The ultimate bearing capacity of RCFST columns decreased as the eccentricity or lengthdiameter ratio increased. Tang and $\mathrm{Xu}[19,20]$ investigated the seismic behavior of the RCFST column. Test results indicated that the seismic behaviors of the RCFST columns were similar to those of the corresponding ordinary CFST columns, and it was feasible to apply these RCFST columns in seismic areas. Geng et al. [21] carried out an experiment on the time-dependent behavior of RCFST columns. Tests results revealed that the total deformation of RCFST columns could increase by up to $50 \%$ after five months subjected to sustained loading, which was $22 \%$ higher than that of the ordinary CFST columns.

These above studies demonstrate the feasibility of RCFST in engineering application and strengthen the concept of environmental protection and sustainability in engineering. However, the uncompactness of core concrete in this composite structure is easy to occur due to insufficient vibration and the irremovable air in the steel tube. This uncompactness defect may decrease the bearing capacity of specimens. Hence, Mahgub et al. [22] investigated the mechanical behavior of self-compacting concrete-filled elliptical steel tubular columns subjected to axial load. Results indicated that specimens with large slenderness ratio exhibited global buckling failure modes, and the ultimate strength decreased as the slenderness ratio increased, while it increased as the strength grade of concrete increased. Muciaccia et al. [23] conducted the experiments on the response of self-compacting concretefilled steel tubular (SCFST) columns under eccentric compression. Three different concrete, such as a selfcompacting concrete, an ordinary vibrated concrete, and an expansive SCC, were employed to investigate the behavior of SCFST columns subjected to eccentric compression. Elzbieta and Piot [24] tested the bonding behavior between outer steel tube and core self-compacting concrete in composite tube columns. The results indicated that the bonding performance of SCFST columns depends on the compressive strength of concrete, and the bond strength of self-compacting concrete was lower than that of vibration concrete. Ding and $\mathrm{Yu}$ [25] studied the pure bending behavior of SCFST columns. The effect of the strength grade of concrete on the flexural capacities was not obvious. However, the flexural capacities increased remarkably as the steel ratio increased. Moreover, Dotreppe et al. [26] carried out a numerical study using the nonlinear finite element software SAFIR to investigate the structural and thermal properties of SCFST columns under fire conditions. The results revealed that the mechanical behaviors of SCFST columns at high temperatures were similar to those of normal CFST columns, and the application of these columns in practical engineering buildings was feasible.

In summary, a lot of theoretical and experimental investigations have been carried out on RCFST and SCFST. However, few studies were focused on the behaviors of RSCFCST columns. In this analysis, twenty-one RSCFCST columns under eccentric compression are tested to investigate the performance of stiffness.

\section{Experimental Program}

2.1. Preparation of Specimens. Twenty-one specimens, including fifteen RSCFCST short columns and six RSCFCST long columns under an eccentric load, were carried out. Four parameters, such as length-diameter ratio, replacement ratio of RCA, strength grade of concrete, and eccentricity, were examined in this analysis. The outer diameter of the steel tube is $140 \mathrm{~mm}$, and the thickness of steel tube is $3.63 \mathrm{~mm}$. The lengths of the steel tube are $500 \mathrm{~mm}, 1000 \mathrm{~mm}$, and $1500 \mathrm{~mm}$, respectively. Different length-diameter ratios (i.e., $3.57,7.14$, and 10.71), replacement ratios of RCA (i.e., $0 \%$, $50 \%$, and $100 \%$ ), strength grades of concrete (i.e., C30, C50, and C60), and eccentricities (i.e., $20 \mathrm{~mm}, 40 \mathrm{~mm}$, and $60 \mathrm{~mm}$ ) were adopted. The specific parameters of the specimens are listed in Table 1.

A $300 \mathrm{~mm} \times 300 \mathrm{~mm} \times 10 \mathrm{~mm}$ steel plate was first welded to the bottom of the steel tube. Then, recycled self-compacting concrete (RSC) was poured into the steel tube. After the core RSC reached the initial setting strength, a plastic film was used to wrap the top of the steel tube. Seven days later, this plastic film was removed, and another $300 \mathrm{~mm} \times 300 \mathrm{~mm} \times 10 \mathrm{~mm}$ steel plate was welded on the top of the steel tube.

2.2. Mechanical Properties of Materials. RSCFCST column is a composite structure consisting of a outer seamless steel tube and RSC infill. According to "Metallic material-Tensile testing (GB/T228-2010)" Part I [27], the yield and ultimate strength of the outer steel tube determined from the coupon test are $233.1 \mathrm{MPa}$ and $295.7 \mathrm{MPa}$, respectively. Young's modulus and Poisson's ratio of the steel tube are $2.0 \times 10^{5} \mathrm{MPa}$ and 0.297 , respectively.

RSC is made of RCA, fine aggregate, Portland cement, tap water, high-performance water-reducing agent, and natural macadam. The coarse aggregate consisted of continuously graded gravel and RCA. The particle size range of RCA and graded gravel is $5 \mathrm{~mm} \sim 31.5 \mathrm{~mm}$. RCA was obtained by crushing the waste concrete blocks with a strength of C20 C60. The sieve analysis of RCA was performed according to the Chinese code JGJ 52-2006 [28]. The fine aggregate consisted of fly ash and graded sand. The bulk density of fly ash is $2.2 \mathrm{~g} / \mathrm{cm}^{3}$. The fineness modulus of sand is 2.9. Table 2 depicts the mix proportion of RSC with different strength grades and the corresponding mechanical properties determined from the specified test approach according to regulation JGJ/T283-2012 [29]. 
TABle 1: Parameters of RSCFCST columns.

\begin{tabular}{|c|c|c|c|c|c|c|c|c|c|}
\hline Specimen ID & $D(\mathrm{~mm})$ & $t(\mathrm{~mm})$ & $L(\mathrm{~mm})$ & $\gamma(\%)$ & $e(\mathrm{~mm})$ & $e / r$ & $L / D$ & Concrete number/grade & $N_{\mathrm{u}}$ \\
\hline RSCSE-1 & 140 & 3.63 & 500 & 0 & 20 & 0.3 & 3.57 & S1/C30 & 819 \\
\hline RSCSE-2 & 140 & 3.63 & 500 & 0 & 40 & 0.6 & 3.57 & S1/C30 & 603 \\
\hline RSCSE-3 & 140 & 3.63 & 500 & 0 & 60 & 0.9 & 3.57 & $\mathrm{~S} 1 / \mathrm{C} 30$ & 512 \\
\hline RSCSE-4 & 140 & 3.63 & 500 & 50 & 20 & 0.3 & 3.57 & $\mathrm{~S} 2 / \mathrm{C} 30$ & 776 \\
\hline RSCSE-5 & 140 & 3.63 & 500 & 50 & 40 & 0.6 & 3.57 & $\mathrm{~S} 2 / \mathrm{C} 30$ & 557 \\
\hline RSCSE-6 & 140 & 3.63 & 500 & 50 & 60 & 0.9 & 3.57 & $\mathrm{~S} 2 / \mathrm{C} 30$ & 457 \\
\hline RSCSE-7 & 140 & 3.63 & 500 & 100 & 20 & 0.3 & 3.57 & $\mathrm{~S} 3 / \mathrm{C} 30$ & 761 \\
\hline RSCSE-8 & 140 & 3.63 & 500 & 100 & 40 & 0.6 & 3.57 & S3/C30 & 552 \\
\hline RSCSE-9 & 140 & 3.63 & 500 & 100 & 60 & 0.9 & 3.57 & S3/C30 & 441 \\
\hline RSCSE-10 & 140 & 3.63 & 500 & 100 & 20 & 0.3 & 3.57 & S4/C50 & 893 \\
\hline RSCSE-11 & 140 & 3.63 & 500 & 100 & 40 & 0.6 & 3.57 & S4/C50 & 670 \\
\hline RSCSE-12 & 140 & 3.63 & 500 & 100 & 60 & 0.9 & 3.57 & S4/C50 & 504 \\
\hline RSCSE-13 & 140 & 3.63 & 500 & 100 & 20 & 0.3 & 3.57 & S5/C60 & 898 \\
\hline RSCSE-14 & 140 & 3.63 & 500 & 100 & 40 & 0.6 & 3.57 & S5/C60 & 672 \\
\hline RSCSE-15 & 140 & 3.63 & 500 & 100 & 60 & 0.9 & 3.57 & S5/C60 & 585 \\
\hline RSCSE-16 & 140 & 3.63 & 1000 & 100 & 20 & 0.3 & 7.14 & S4/C50 & 883 \\
\hline RSCSE-17 & 140 & 3.63 & 1000 & 100 & 40 & 0.6 & 7.14 & S4/C50 & 604 \\
\hline RSCSE-18 & 140 & 3.63 & 1000 & 100 & 60 & 0.9 & 7.14 & S4/C50 & 481 \\
\hline RSCSE-19 & 140 & 3.63 & 1500 & 100 & 20 & 0.3 & 10.71 & S4/C50 & 748 \\
\hline RSCSE-20 & 140 & 3.63 & 1500 & 100 & 40 & 0.6 & 10.71 & S4/C50 & 518 \\
\hline RSCSE-21 & 140 & 3.63 & 1500 & 100 & 60 & 0.9 & 10.71 & S4/C50 & 408 \\
\hline
\end{tabular}

Note. $D$ is the outer diameter of steel tube; $t$ and $L$ are the measured thickness and length of the steel tube, respectively; $\gamma$ is the replacement ratio of RCA; $e$ is the eccentricity of specimen; $r$ is the radius of RSC; $e / r$ is the eccentricity ratio; $L / D$ is the length-diameter ratio of specimen; $N_{\mathrm{u}}$ is the ultimate load of the specimen.

TABLE 2: Mix proportion and mechanical properties of RSC.

\begin{tabular}{|c|c|c|c|c|c|c|c|c|c|c|c|}
\hline $\begin{array}{l}\text { Number } \\
\text { ID }\end{array}$ & $\begin{array}{l}\text { Water } \\
\left(\mathrm{kg} / \mathrm{m}^{3}\right)\end{array}$ & $\begin{array}{c}\text { Sand } \\
\left(\mathrm{kg} / \mathrm{m}^{3}\right)\end{array}$ & $\begin{array}{l}\text { Cement } \\
\left(\mathrm{kg} / \mathrm{m}^{3}\right)\end{array}$ & $\begin{array}{l}\text { Fly ash } \\
\left(\mathrm{kg} / \mathrm{m}^{3}\right)\end{array}$ & $\begin{array}{l}\text { Water- } \\
\text { reducing } \\
\text { agent } \\
\left(\mathrm{kg} / \mathrm{m}^{3}\right)\end{array}$ & $\begin{array}{c}\text { Natural } \\
\text { macadam } \\
\left(\mathrm{kg} / \mathrm{m}^{3}\right)\end{array}$ & $\begin{array}{c}\text { RCA } \\
\left(\mathrm{kg} / \mathrm{m}^{3}\right)\end{array}$ & $\begin{array}{l}\text { Cube } \\
\text { strength } \\
(\mathrm{MPa})\end{array}$ & $\begin{array}{c}\text { Compressive } \\
\text { strength } \\
(\mathrm{MPa})\end{array}$ & $\begin{array}{l}\text { Poisson's } \\
\text { ratio }\end{array}$ & $\begin{array}{l}\text { Elasticity } \\
\text { modulus } \\
\left(10^{4} \mathrm{MPa}\right)\end{array}$ \\
\hline S1 & 210 & 736 & 305 & 144 & 3.143 & 798 & 0 & 36.2 & 29.1 & 0.217 & 2.63 \\
\hline S2 & 210 & 736 & 305 & 144 & 3.143 & 399 & 399 & 34.6 & 27.8 & 0.174 & 2.57 \\
\hline S3 & 210 & 736 & 305 & 144 & 3.143 & 0 & 798 & 33.0 & 26.3 & 0.152 & 2.31 \\
\hline S4 & 176 & 936 & 395 & 151 & 1.638 & 0 & 798 & 53.4 & 42.8 & 0.168 & 2.73 \\
\hline S5 & 164 & 736 & 477 & 113 & 1.770 & 0 & 798 & 61.8 & 49.5 & 0.165 & 3.02 \\
\hline
\end{tabular}

2.3. Test Setup and Loading Scheme. Monotone static loading tests were carried out on the electron-hydraulic servo pressure machine Type YAW-5000F. Adjustable V-blocks and a knife edge were prepared for the tests to get the required eccentricity, as shown in Figure 1. Two linear variable displacement transducers (LVDTs) were diagonally arranged on the bottom loading plate to monitor the RSCFCST column's axial deformation. Another three LVDTs were arranged at the height of $1 / 4,1 / 2$, and $3 / 4$ of the columns to measure the bending deflections of the specimen. For the RSCFCST short column, eight strain gauges were evenly glued at the midheight of column, as shown in Figure 2(a), to determine the axial and circumferential strains of the outer steel tube. For the RSCFCST long column, as shown in Figure 2(b), twenty-four strain gauges were evenly arranged at the height of $1 / 4,1 / 2$, and $3 / 4$ of specimen.

In this test, load-controlled and displacement-controlled loading scheme were adopted. Initially, the load-controlled loading scheme was applied, and the loading rate was $50 \mathrm{kN} /$ min. As the load increased to approximately $85 \%$ of the estimated ultimate strength of specimen, the displacement- controlled loading scheme was then adopted, and the loading rate was $0.5 \mathrm{~mm} / \mathrm{min}$.

\section{Experimental Results and Analysis}

3.1. Failure Mode. According to the test results, the failure process of the RSCFCST column experiences three stages as elasticity, elastoplasticity, and failure. Several phenomena, including the gradual falling of the rust on the surface of the steel tube, the local yielding of the outer steel tube, occasionally the sound of RSC crushing, and the local buckling of specimen, are observed in the tests. Two failure modes of the RSCFCST columns under eccentric compression are demonstrated, as shown in Figure 3. The RSCFCST short columns under eccentric compression exhibit drum-like bending failures, while the RSCFCST long columns experience the global flexural buckling failure modes.

3.2. Load-Stiffness Curves. Figure 4 illustrates the influence of various parameters, such as strength grade of concrete, replacement ratio of RCA, eccentricity, and length-diameter 


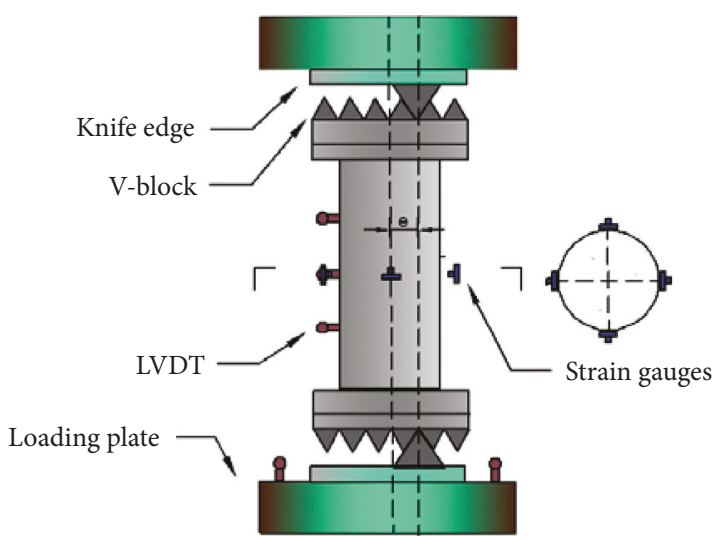

(a)

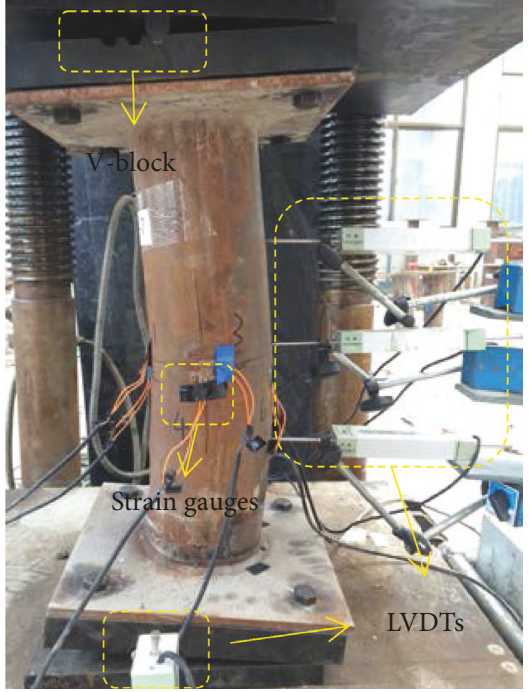

(b)

Figure 1: Test setup and strain measuring point arrangement: (a) schematic diagram of test setup; (b) Test setup.

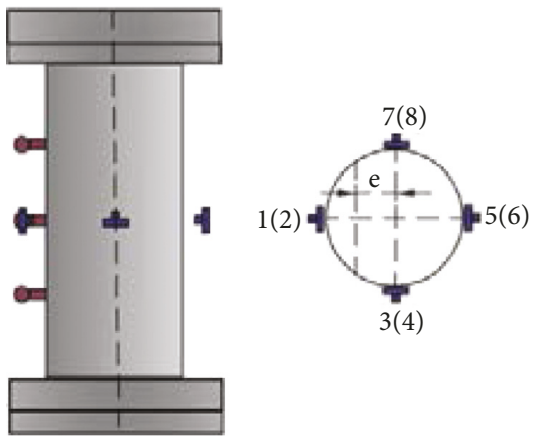

(a)

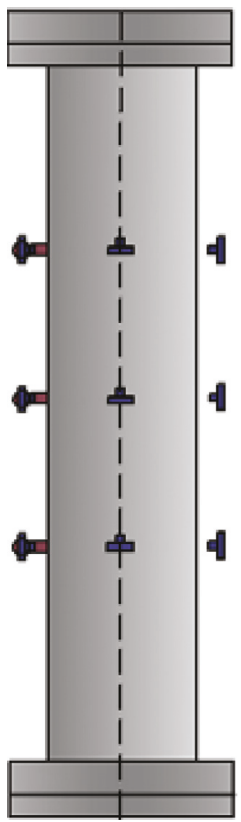

(b)

FIGURE 2: Strain arrangement: (a) short column; (b) long column.

ratio, on the load-stiffness relationship of RSCFCST columns under an eccentric load. $K$ denotes the stiffness of the specimen, and $N_{\mathrm{e}}$ represents the axial load.

3.2.1. Effect of Strength Grade of Concrete. Figure 4(a) depicts the effect of the concrete strength grade on the loadstiffness relationship of specimen. Obviously, the strength grade of concrete has a significant effect on the stiffness and bearing capacity of specimen. Initially, the load-stiffness curves are basically horizontal, and the initial stiffness increases as the strength grade of concrete increases. Take RSCSE-7 and RSCSE-13 for example, the initial stiffness of RSCSE-13 is approximately 2.4 times of that of RSCSE-7. With the increase of load, the stiffness degradation rate of specimens is increased gradually and the increase of concrete strength grade would deteriorate the concrete degradation. As depicted in Figure 4(a), the ultimate bearing capacity of the RSCFCST column increases as the strength grade of concrete increases. For example, the ultimate bearing capacity of RSCSE-13 is about $16 \%$ higher than that of RSCSE7. The reason is that the compressive strength, the elastic 


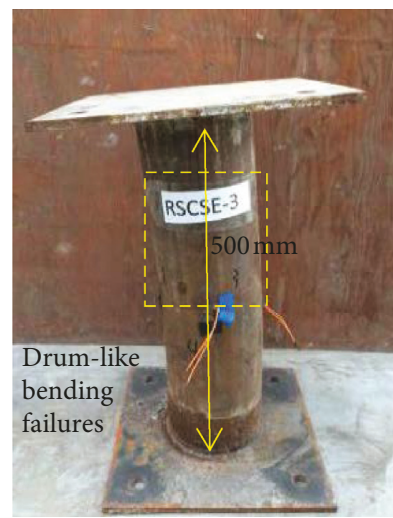

(a)

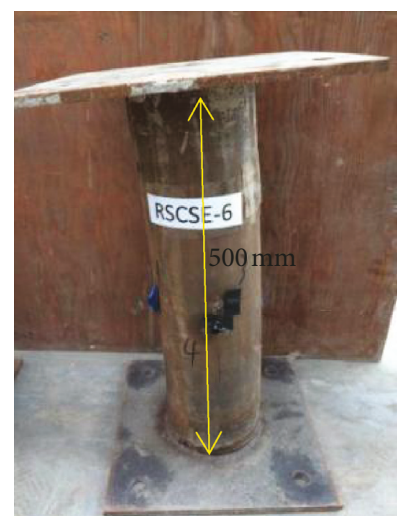

(b)

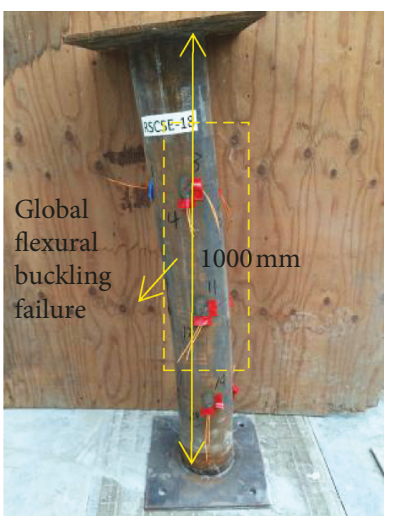

(c)

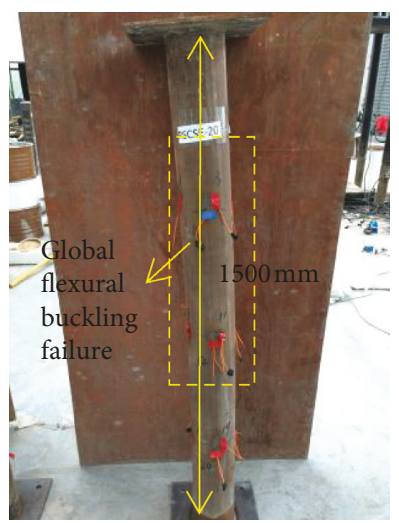

(d)

FIgURE 3: Failure modes of the RSCFCST columns: (a) RSCSE-3; (b) RSCSE-6; (c) RSCSE-18; (d) RSCSE-21.

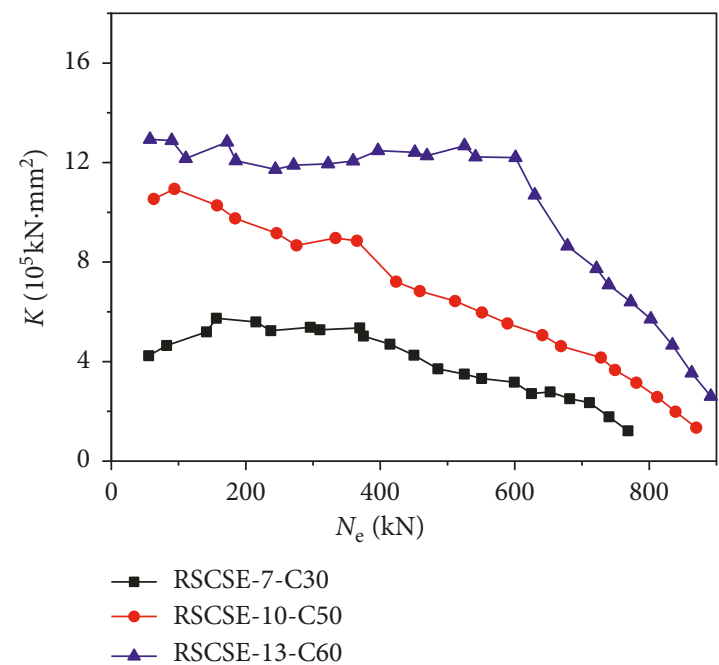

(a)

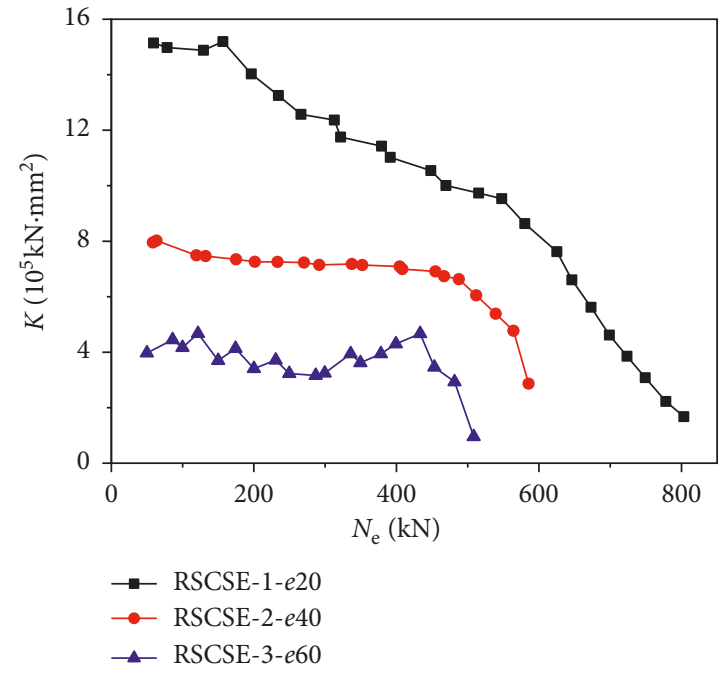

(c)

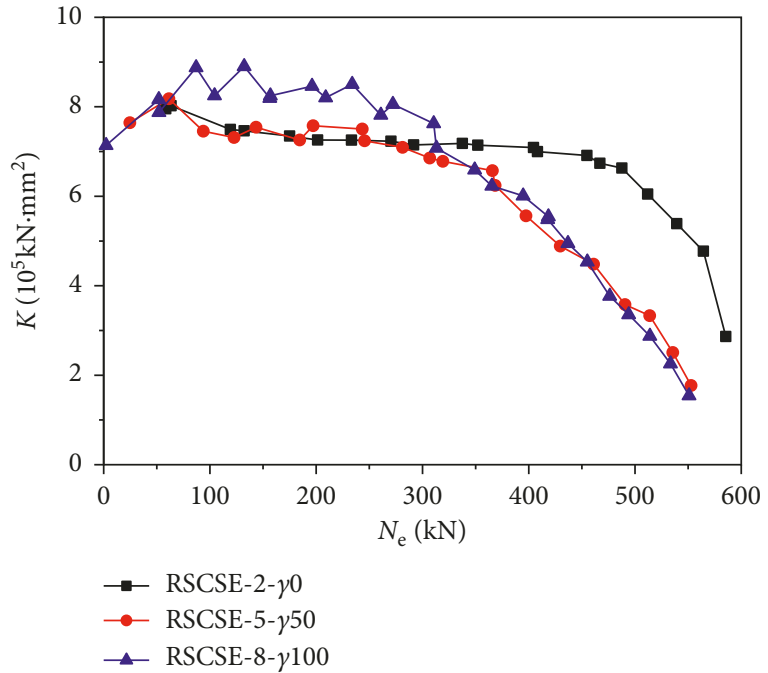

(b)

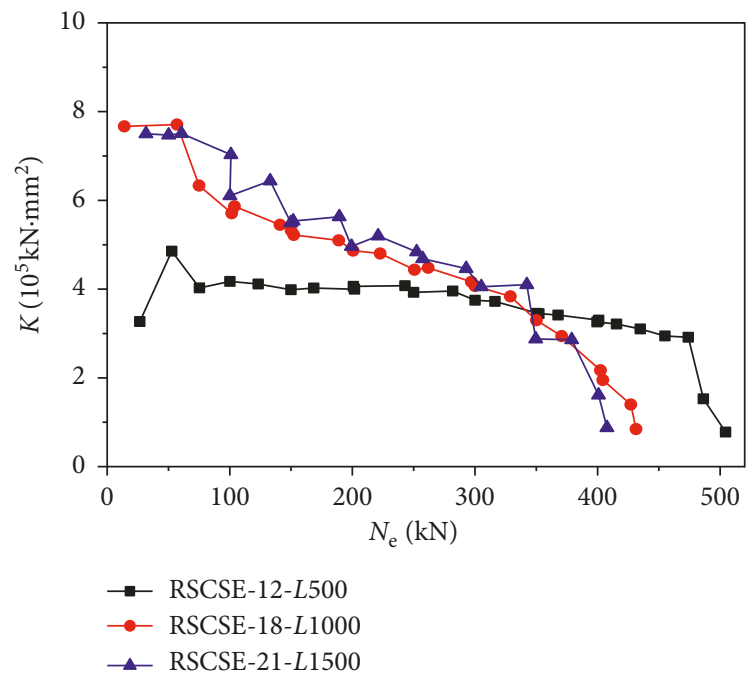

(d)

FIGURE 4: Load-stiffness curves: (a) effect of strength grade of concrete ( $e=20 \mathrm{~mm}$ ); (b) effect of replacement ratio of RCA (e=40 mm); (c) effect of eccentricity (C30- $\gamma$ 0-L500); (d) effect of length-diameter ratio $(e=60 \mathrm{~mm})$. 
modulus, and the compactness of core RSC increase as the strength grade of concrete increases.

\subsubsection{Effect of Replacement Ratio of RCA. Figure 4(b) il-} lustrates the effect of the replacement ratio of RCA on the stiffness of eccentrically loaded RSCFCST columns. The replacement ratio of RCA has little effect on the stiffness of specimen in the elastic stage, and the load-stiffness curves are approximately horizontal. As the load increases, the curve shows an obvious inflection point, and the specimen enters the elastoplastic stage. The increase in the replacement ratio of RCA accelerates the stiffness degradation of specimens. Generally, the specimens with a higher replacement ratio of RCA have shorter load-stiffness horizontal stage and longer slow descent stage. The ultimate bearing capacity of RSCFCST columns under an eccentric load slightly decreases as the replacement ratio of RCA increases. For example, the ultimate bearing capacity of RSCSE-2 is $5 \%$ higher than that of RSCSE-8. This may come from that the increase in the replacement ratio of RCA increases the interface between mortar adhered to the surface of RCA, which accelerates the stiffness degradation of specimen and slightly decreases the bearing capacity of RSCFCST columns.

3.2.3. Effect of Eccentricity. As depicted in Figure 4(c), eccentricity has a remarkable effect on the stiffness and bearing capacity of specimens. In the initial loading stage, the load-stiffness curve of the specimen presents a horizontal stage approximately. The initial stiffness of specimens decreases as the eccentricity increases. For example, the initial stiffness of RSCSE- 1 is about 4 times of that of RSCSE-3. With the increase of the load, the load-stiffness curve deviates from the horizontal and the stiffness degradation rate of specimen is increased. The ultimate bearing capacity of specimen decreases with the increase of eccentricity. Take RSCSE-1 and RSCSE-3 for example; the ultimate bearing capacity of RSCSE-13 is 60\% higher than that of RSCSE-7. This may come from that the failure of specimens under the axial load is full section compression failure, while partial tension and partial compression occur in the failure section of eccentric compression specimens. The confinement effect of the steel tube on core RSC only occurs in the compression zone. The larger the eccentricity is, the smaller the cross-sectional area of the compression is in the failure zone. Therefore, the confinement effect decreases as the eccentricity increases. Moreover, the increase of the eccentricity enlarges the second-order effect and increases the lateral deflection.

3.2.4. Effect of Length-Diameter Ratio. Figure 4(d) reveals the influence of the length-diameter ratio on the stiffness of RSCFCST columns under eccentric compression. Initially, the load-stiffness curve of specimen presents a horizontal stage approximately as the specimen is in the elastic stage. Obviously, with the increase of load, the increase of lengthdiameter ratio would accelerate the stiffness degradation of specimen. The ultimate bearing capacity of the RSCFCST column under eccentric load decreases as the length-diameter ratio increases. For example, the ultimate bearing capacity of RSCSE-12 is $24 \%$ higher than that of RSCSE- 21 . The reason is that the increase of the length-diameter ratio would cause the instability of specimen under eccentric load. The deflection of the specimens increases as the lengthdiameter ratio increases. The additional deflection magnifies the $P-\delta$ effect of specimen reducing the bearing capacity and bending stiffness of specimen.

3.3. Stress-Strain Analysis. The stress-strain curves of the RSCFCST columns subjected to eccentric compression are shown in Figures 5-8. In these figures, $\sigma$ represents the compressive stress of specimen, $\varepsilon_{1}$ is the longitudinal strain, and $\varepsilon_{\mathrm{c}}$ is the circumferential strain.

3.3.1. Effect of Strength Grade of Concrete. The effect of concrete strength grade on the stress-strain relationship of RSCFCST columns under eccentric compression is illustrated in Figure 5. Initially, the stress-strain curves of concrete with different strength grades are linearly increased, and the strength grade of concrete has little effect on the stress-strain curve in the elastic stage. As the load increases, the stress-strain curve of specimen increases nonlinearly, and an inflection point appears on the stress-strain curve. The longitudinal compressive strain develops faster than the longitudinal tensile strain, and the circumferential tensile strain develops faster than the compressive strain. As the strength grade of concrete increases, the stress of specimen increases while the strain development rate decreases.

3.3.2. Effect of Replacement Ratio of RCA. As shown in Figure 6, the effect of the replacement ratio of RCA on the stress-strain relationship of RSCFCST columns under eccentric compression is not obvious in the elastic stage. With the increase of the load, the stress-strain curve deviates from linear growth. The circumferential tensile strain develops faster than the circumferential compression strain. Besides, the longitudinal compressive strain develops faster than the longitudinal tensile strain. Strain growth accelerates as the replacement ratio of RCA increases.

3.3.3. Effect of Eccentricity. The slope of the stress-strain curve decreases with the increase of eccentricity, as shown in Figure 7. For the specimen with small eccentricity, the whole section is in the compressive state at the initial of loading, and all strains on the section are compressive. With the increase of eccentricity, the yield and ultimate stress of specimen decrease, while the strains develop quickly.

3.3.4. Effect of Length-Diameter Ratio. Initially, the stressstrain curves of specimens with different length-diameter ratios are linearly increased, as shown in Figure 8. As load 


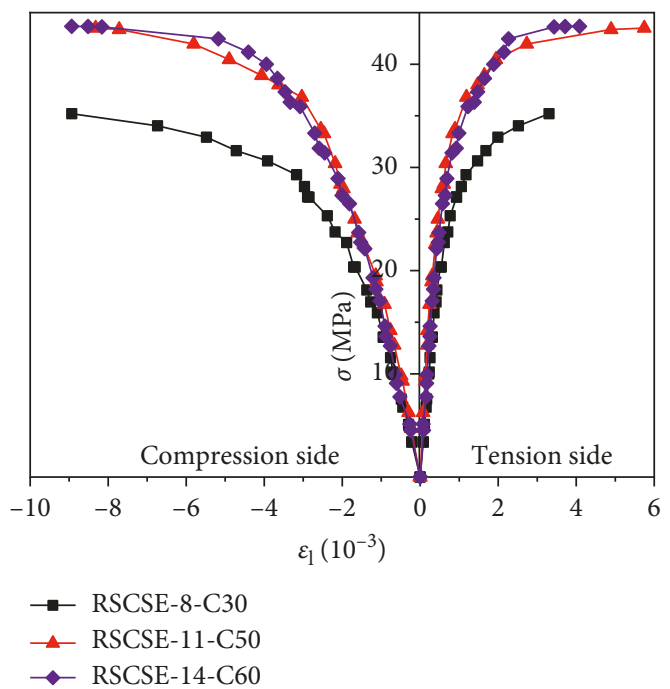

(a)

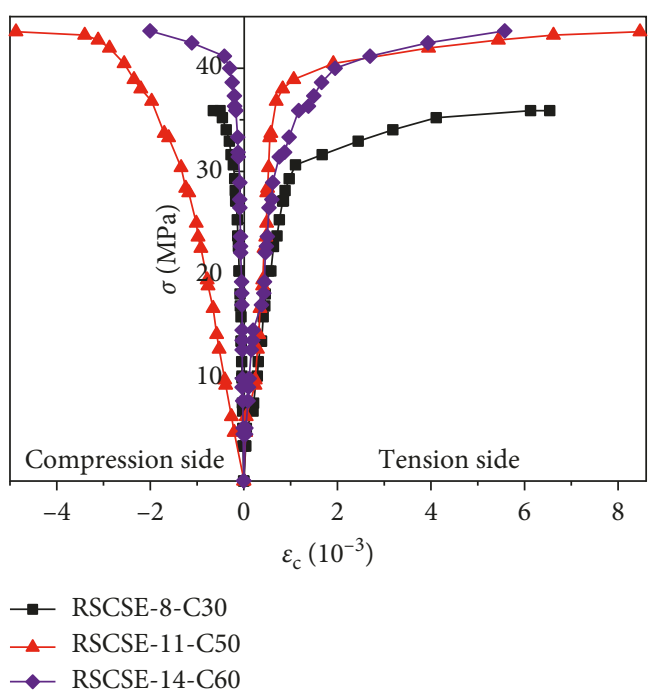

(b)

FIGURE 5: Effect of grade strength of concrete on the stress-strain curve $(e=40 \mathrm{~mm})$ : (a) longitudinal strain; (b) circumferential strain.

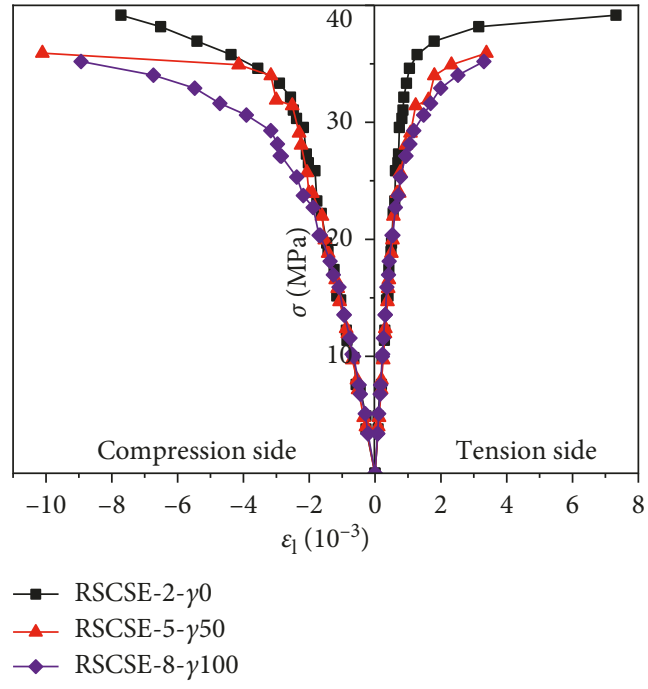

(a)

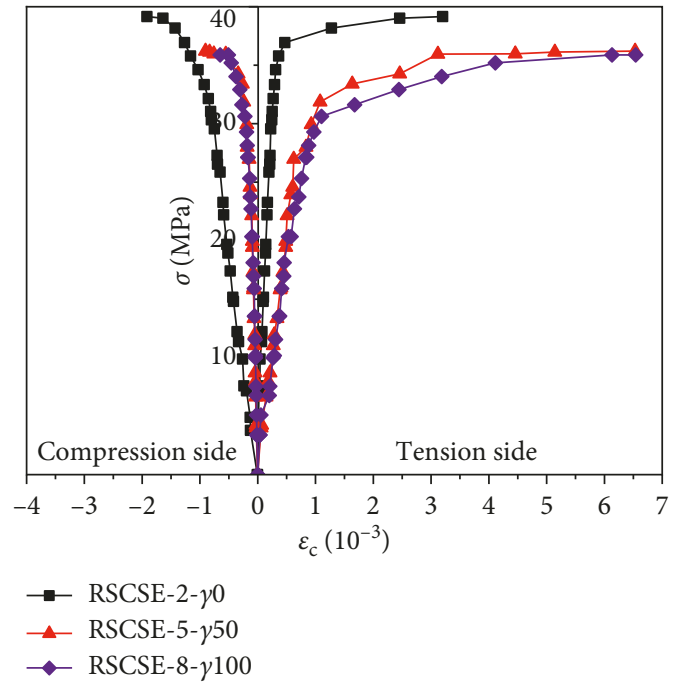

(b)

FIGURE 6: Effect of replacement ratio of RCA on the stress-strain curve (e=40 mm): (a) longitudinal strain; (b) circumferential strain.

increases, the stress-strain curve deviates from linearity, and an inflection point appears on the stress-strain curve. The increase of the length-diameter ratio would decrease the stress of specimen and increase the strain growth rate.

\section{A Modified Model for Predicting the Effective Stiffness}

4.1. Basic Assumption. To simplify the effective stiffness calculation of the RSCFCST columns under eccentric compression, the following assumptions are made: (1) the plane section hypothesis is applied for the whole calculation; (2) outer steel tube and core RSC work and deform coordinately; (3) the deflection curve is approximately in the shape of a half sine wave.
4.2. A New Model for Estimating the Effective Stiffness. For the conventional CFST columns, the estimation of the stiffness $B$ under axial compression is suggested by the following well-known equation [30]:

$$
B={ }_{s} E_{s} I+{ }_{c} E_{c} I \text {, }
$$

where ${ }_{c} E$ and ${ }_{s} E$ are the elastic modulus of core concrete and outer steel tube, respectively, and ${ }_{c} I$ and ${ }_{s} I$ are the crosssectional moment of inertia of core concrete and outer steel tube, respectively.

However, few investigations are focused on predicting the effective stiffness of concrete-filled steel tubular composite columns under eccentric compression. According to $[31,32]$, the effective stiffness of the composite structure needs a certain reduction since the interface interaction 


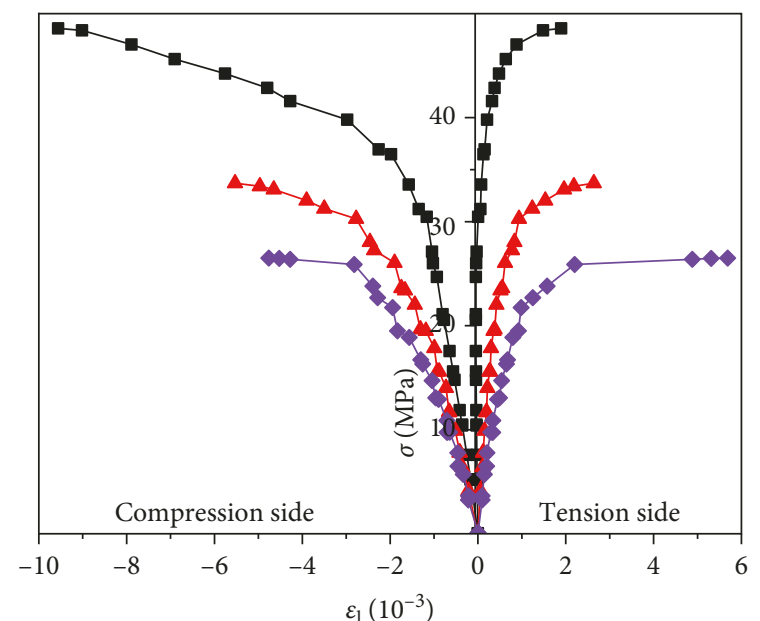

- RSCSE-19-e20
- RSCSE-20-e40
- - RSCSE-21-e60

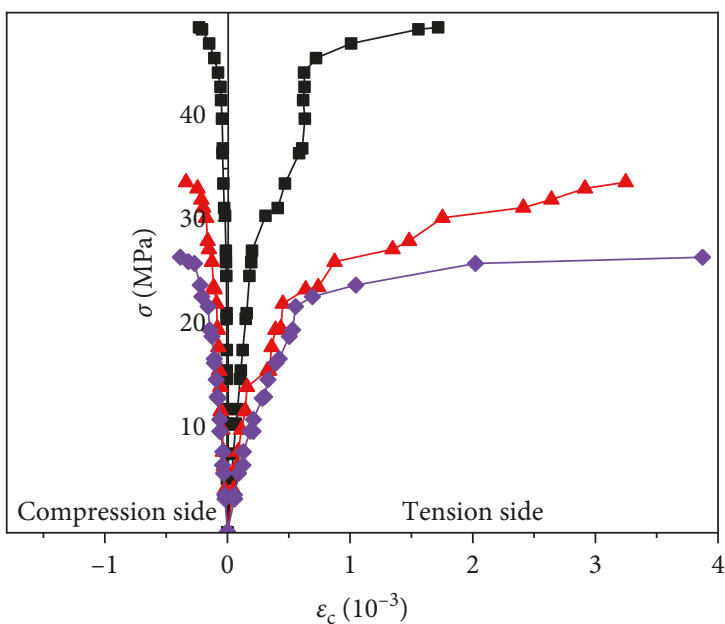

$\rightarrow$ RSCSE-19-e20
$\longleftarrow$ RSCSE-20-e40
- RSCSE-21-e60

(a)

(b)

FiguRE 7: Effect of eccentricity on the stress-strain curve (C60- $\gamma 100-\mathrm{L} 500)$ : (a) longitudinal strain; (b) circumferential strain.

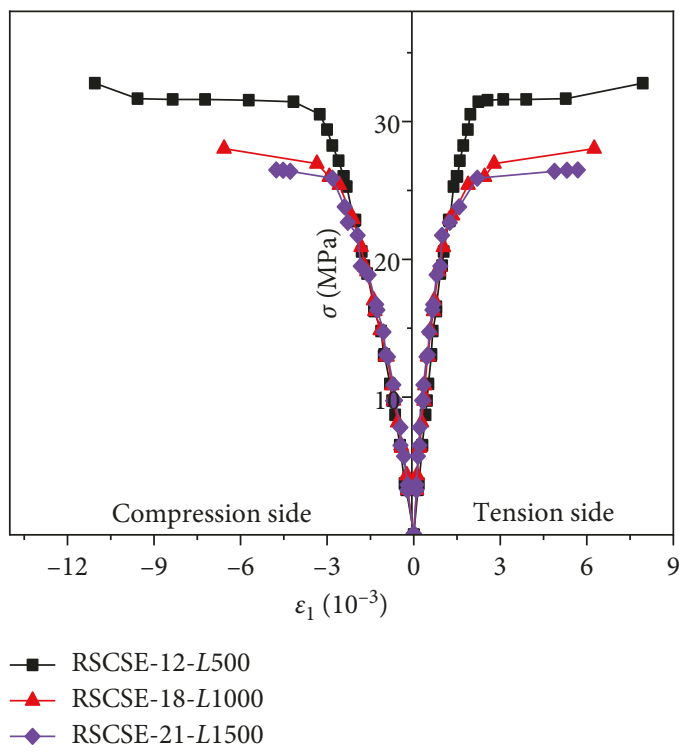

(a)

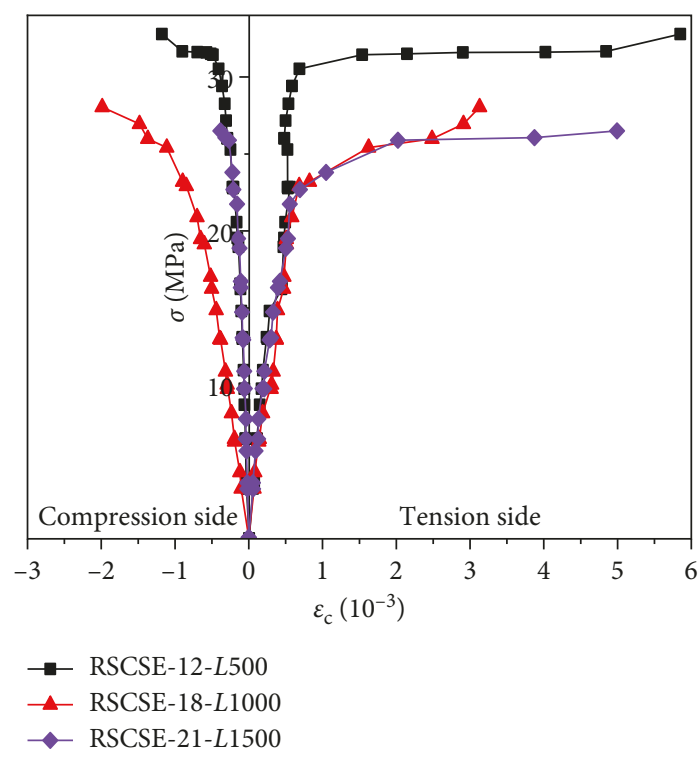

(b)

FIGURE 8: Effect of length-diameter ratio on the stress-strain curve $(e=60 \mathrm{~mm})$ : (a) longitudinal strain; (b) circumferential strain.

should be taken into consideration. Therefore, an effective stiffness factor $\lambda$ is introduced in this study, and the effective stiffness of RSCFCST columns under eccentric compression can be expressed as follows:

$$
B_{\mathrm{sc}}=\lambda(\mathrm{EI})_{\mathrm{sc}}=\lambda\left(E_{\mathrm{s}} I_{\mathrm{s}}+E_{\mathrm{c}} I_{\mathrm{c}}\right),
$$

where $B_{\mathrm{sc}}$ is the effective stiffness of RSCFCST columns under eccentric compression; $E_{\mathrm{c}}$ is the elastic modulus of RSC; $I_{\mathrm{c}}$ and $I_{\mathrm{s}}$ are the cross-sectional moment of inertia of the RSC and outer steel tube, respectively; and $E_{\mathrm{c}}$ is obtained by multiple regression of test data as follows:

$$
E_{\mathrm{c}}=30356.47 \gamma+348127.7 \beta_{\gamma}+307.2244 f_{\mathrm{ck}}-330280 \text {, }
$$

where $\beta_{\gamma}$ is the correction coefficient considering the influence of the replacement ratio of RCA, which is fitted by the regression analysis of the existing test data, as shown in Figure 9 and the following equation:

$$
\beta_{\gamma}=1-0.082 \gamma-0.013 \gamma^{2} \text {. }
$$

For the slender columns, the second-order effect should be taken into account. There are two main methods such as 


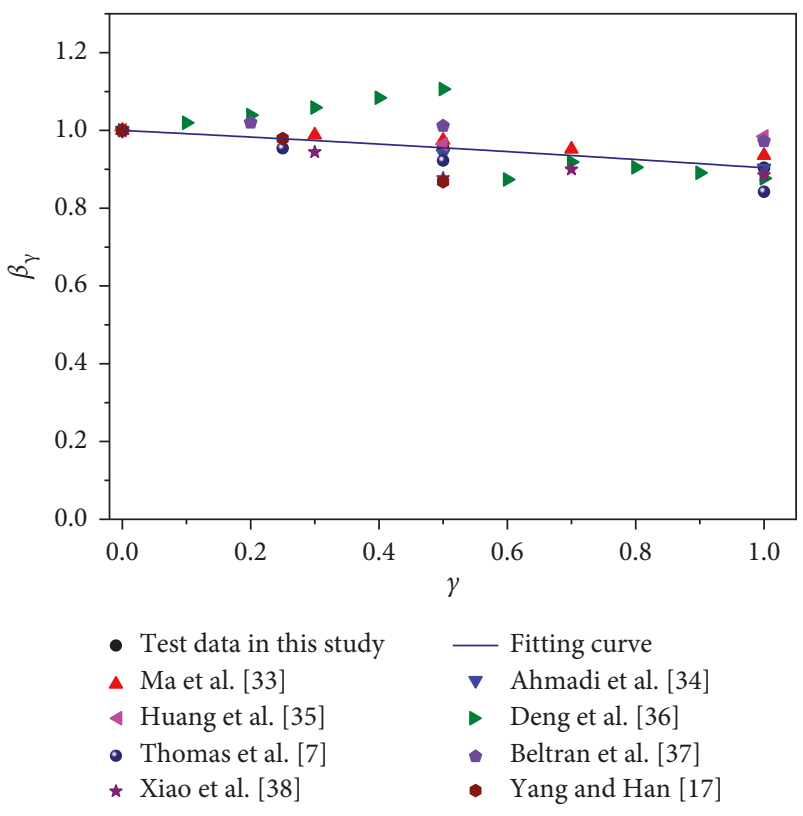

Figure 9: Relationship between $\beta_{\gamma}$ and $\gamma$.

the nominal curvature approach and the moment magnifier approach to consider the second-order effect in current specifications. The precision of the moment magnifier approach relies on $B_{\mathrm{sc}}$ of the specimen and has been employed by Eurocode 4 [39], ACI-318 [40], etc. In the specifications, the magnification coefficient $\eta$ can be established:

$$
\eta=1+\frac{\Delta}{e}=\frac{1}{1-N_{\mathrm{u}} / N_{\mathrm{cr}}},
$$

where $N_{\mathrm{u}}$ is the ultimate load of the specimen and $N_{\mathrm{cr}}$ is the critical buckling strength, which is related to $L$ and $B_{\mathrm{sc}} . N_{\mathrm{cr}}$ can be estimated by the following equation:

$$
N_{\mathrm{cr}}=\frac{\pi^{2} B_{\mathrm{sc}}}{L^{2}}
$$

According to the above equations, $B_{\mathrm{sc}}$ can be described as follows:

$$
B_{\mathrm{sc}}=\frac{N_{\mathrm{u}} L^{2}}{\pi^{2}(1-(1 /(1+(\Delta / e))))} .
$$

According to equations (2) and (7), the effective stiffness factor $\lambda$ of the RSCFCST columns under eccentric compression can be expressed as follows:

$$
\lambda=\frac{N_{\mathrm{u}} L^{2}}{\pi^{2}(1-(1 /(1+(\Delta / e))))\left(E_{\mathrm{s}} I_{\mathrm{s}}+E_{\mathrm{c}} I_{\mathrm{c}}\right)} .
$$

For the RSCFCST stub columns subjected to eccentric load $(L / D \leq 4)$ [41], the failure modes of specimens are mainly compressive failure of core RSC. Therefore, the effective stiffness factor $(\lambda)$ mainly considers the influence of $e / r$ and $L / D$. The effect of the yield strength of the steel tube $\left(f_{\mathrm{y}}\right)$ on the effective stiffness factor $(\lambda)$ is not obvious. $\lambda$ is fitted by the test data, as shown in the following equation:

$$
\lambda_{1}=0.004 \frac{e}{r}-0.0596 \frac{L}{D}+0.3 .
$$

For the RSCFCST long columns under eccentric compression $(L / D>4)$ [41], the failure modes of specimens are compressive failure of core RSC and tension failure of the outer steel tube. Obviously, the influence of $e / r$ and $L / D$ on the effective stiffness factor $(\lambda)$ is significant. Additionally, the effect of the yield strength of the steel $\left(f_{\mathrm{y}}\right)$ and the steel ratio $\alpha\left(\alpha=A_{\mathrm{s}} / A_{\mathrm{c}} \approx 2 t / r\right)$ is not negligible in this case. $\lambda$ is fitted by the experimental data, as shown in the following equation:

$$
\lambda_{2}=-0.0238 \frac{e}{r}+0.045044 \frac{L}{D}-0.00076 \alpha f_{\mathrm{y}}-0.04534 .
$$

The equations for predicting effective stiffness of RSCFCST columns under eccentric compression can be obtained as follows:

$$
B_{\mathrm{sc}}= \begin{cases}\left(0.004 \frac{e}{r}-0.0596 \frac{L}{D}+0.3\right)\left(E_{\mathrm{c}} I_{\mathrm{c}}+E_{\mathrm{s}} I_{\mathrm{s}}\right), & \frac{L}{D} \leq 4, \\ \left(-0.0238 \frac{e}{r}+0.045044 \frac{L}{D}-0.00076 \alpha f_{\mathrm{y}}-0.04534\right)\left(E_{\mathrm{c}} I_{\mathrm{c}}+E_{\mathrm{s}} I_{\mathrm{s}}\right), & \frac{L}{D}>4 .\end{cases}
$$

\section{Nonlinear Finite Element Analysis}

In this study, the mechanical behaviors of RSCFCST columns under eccentric compression are simulated by finite element analysis software ABAQUS 6.12. The finite element analysis model of specimens is established: (1) individual components are established; (2) individual material properties are assigned; (3) mesh sizes are created; (4) components are assembled; (5) analysis steps are defined; and (6) constraints condition, boundary, and loads are applied. A python script supported by ABAQUS [42] is developed to facilitate the execution of the same tasks many times, and the model can be used to conveniently calculate the deflection of specimens.

5.1. Constitutive Relation Model of Materials. As shown in Figure 10, the stress-strain curve of steel can be divided into five stages: elasticity, elastoplasticity, plasticity, hardening, and secondary plastic flow $[43,44]$. The expression of the stress-strain curve is as follows [45]: 


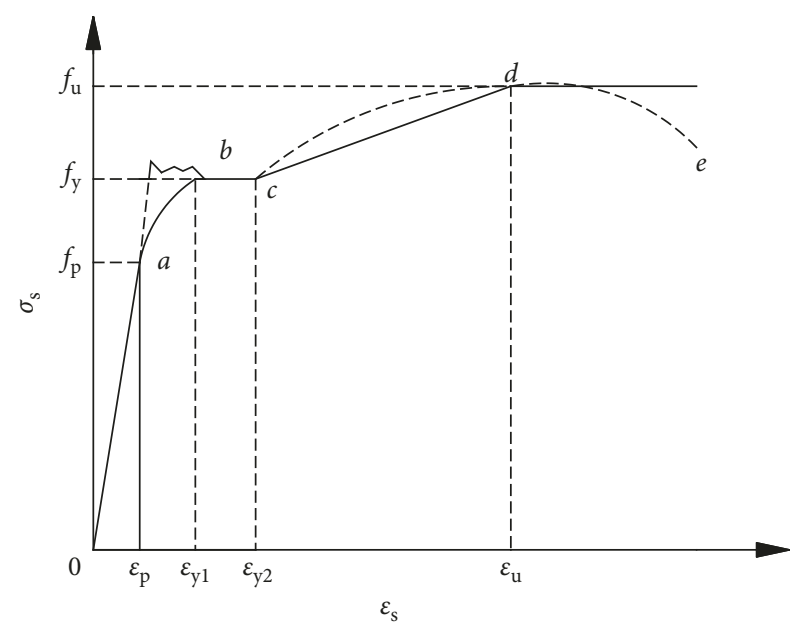

FIgURE 10: Stress-strain curve of steel.

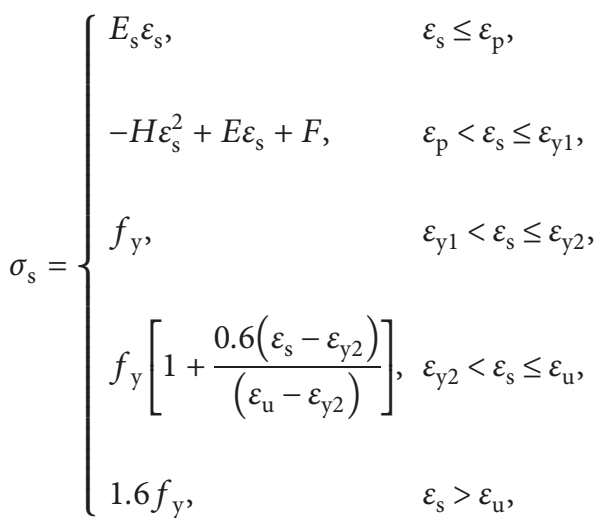

where $\sigma_{s}$ and $\varepsilon_{s}$ denote the equivalent stress and equivalent strain of steel; $E_{\mathrm{s}}$ is the elastic modulus of steel; $f_{\mathrm{y}}$ is the yield strength of the steel; $\varepsilon_{\mathrm{p}}=0.8 f_{\mathrm{y}} / E_{\mathrm{s}}$ is the strain corresponding to the proportional limit of steel; $\varepsilon_{\mathrm{y} 1}=1.5 \varepsilon_{\mathrm{p}}$ is the strain at the starting yield point; $\varepsilon_{\mathrm{y} 2}=10 \varepsilon_{\mathrm{p}}$ is the ending yield point; $\varepsilon_{\mathrm{u}}=100 \varepsilon_{\mathrm{p}}$ is the strain corresponding to ultimate strength of steel; and $H, E$, and $F$ are the parameters of the elastoplastic stage. $H=0.2 f_{\mathrm{y}}\left(\varepsilon_{\mathrm{y} 1}-\varepsilon_{\mathrm{p}}\right)^{2}, E=2 H \varepsilon_{\mathrm{y} 1}$, $F=0.8 f_{\mathrm{y}}+H \varepsilon_{\mathrm{p}}^{2}-E \varepsilon_{\mathrm{p}}, f_{\mathrm{p}}$ is the proportional limit of steel, and $f_{\mathrm{u}}$ is the ultimate strength of steel.

As shown in Figure 11, the effect of the replacement ratio of RCA on the stress-strain relationship is considered and the stress-strain relation of RSC subjected to eccentric load is established in this study based on the existing models $[46,47]$ :

$\frac{\sigma_{\mathrm{c}}}{\sigma_{\mathrm{cp}}}= \begin{cases}g\left(\frac{\varepsilon_{\mathrm{c}}}{\varepsilon_{\mathrm{cp}}}\right)+(3-2 g)\left(\frac{\varepsilon_{\mathrm{c}}}{\varepsilon_{\mathrm{cp}}}\right)^{2}+(g-2)\left(\frac{\varepsilon_{\mathrm{c}}}{\varepsilon_{\mathrm{cp}}}\right)^{3}, & \varepsilon_{\mathrm{c}}<\varepsilon_{\mathrm{cp}}, \\ \frac{\left(\varepsilon_{\mathrm{c}} / \varepsilon_{\mathrm{cp}}\right)}{h\left(\varepsilon_{\mathrm{c}} / \varepsilon_{\mathrm{cp}}-1\right)^{2}+\left(\varepsilon_{\mathrm{c}} / \varepsilon_{\mathrm{cp}}\right)}, & \varepsilon_{\mathrm{c}} \geq \varepsilon_{\mathrm{cp}},\end{cases}$

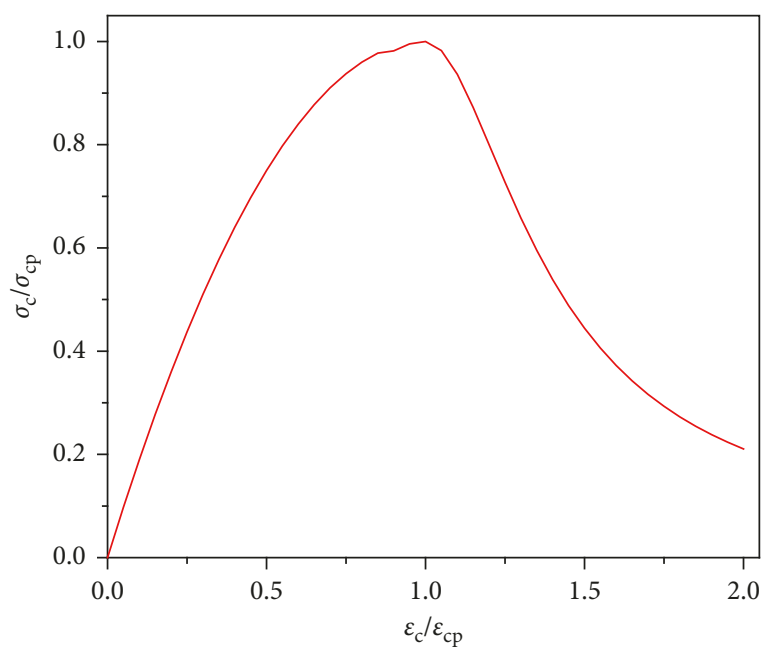

FIGURE 11: Stress-strain curve of core RSC.

where $\sigma_{\mathrm{c}}$ and $\sigma_{\mathrm{cp}}$ represent the compressive stress and maximum compressive stress of RSC, respectively; $\varepsilon_{\mathrm{c}}$ and $\varepsilon_{\mathrm{cp}}$ are the compressive strain and the maximum compressive strain of RSC; $g$ and $h$ are the parameters obtained by regression analysis of test data, as shown in the following equation

$$
\begin{aligned}
& g=2.125-1.171 \gamma-0.0035 f_{c^{\prime}} \\
& h=3.51 \times 10^{-4} \cdot\left(2.36 \times 10^{-5}\right)^{\left[0.25+(\xi-0.5)^{7}\right]} \cdot\left(f_{c}-3.2 \gamma\right)^{2},
\end{aligned}
$$

where $f_{\mathrm{c}}$ is the compressive strength. $\xi=A_{\mathrm{s}} f_{\mathrm{y}} / A_{\mathrm{c}} \beta_{\gamma} f_{\mathrm{ck}}$ is the confinement influence coefficient considering the effect of the replacement ratio of RCA. $A_{\mathrm{s}}=2 \pi(r+t / 2) t$ and $A_{\mathrm{c}}=$ $\pi r^{2} \sin ^{2} \theta$ are the cross-sectional area of the steel tube and core RSC in the compression zone.

The stress-strain model for core RSC in the tension zone is adopted as follows [43]:

$$
\frac{\sigma_{1}}{\sigma_{\mathrm{lp}}}=\left\{\begin{array}{cl}
1.2\left(\frac{\varepsilon_{1}}{\varepsilon_{\mathrm{lp}}}\right)-0.2\left(\frac{\varepsilon_{\mathrm{l}}}{\varepsilon_{\mathrm{lp}}}\right)^{6}, & \varepsilon_{\mathrm{l}}<\varepsilon_{\mathrm{lp}}, \\
\frac{\left(\varepsilon_{\mathrm{l}} / \varepsilon_{\mathrm{lp}}\right)}{0.31 \sigma_{\mathrm{lp}}^{2}\left(\varepsilon_{\mathrm{l}} / \varepsilon_{\mathrm{lp}}-1\right)^{1.7}+\left(\varepsilon_{\mathrm{l}} / \varepsilon_{\mathrm{lp}}\right)}, & \varepsilon_{\mathrm{l}} \geq \varepsilon_{\mathrm{lp}},
\end{array}\right.
$$

where $\sigma_{1}$ and $\sigma_{1 \mathrm{p}}$ stand for the tensile stress and maximum tensile stress of RSC. $\varepsilon_{I}$ and $\varepsilon_{I \mathrm{p}}$ are the tensile strain and the maximum tensile strain of RSC, respectively.

\subsection{Finite Element Model}

5.2.1. Interaction Settings. The constraints between models are defined in the interaction module. Surface-to-surface contact interactions are employed for the surfaces of the steel tube and core RSC [48]. Hard contact is designated as the 


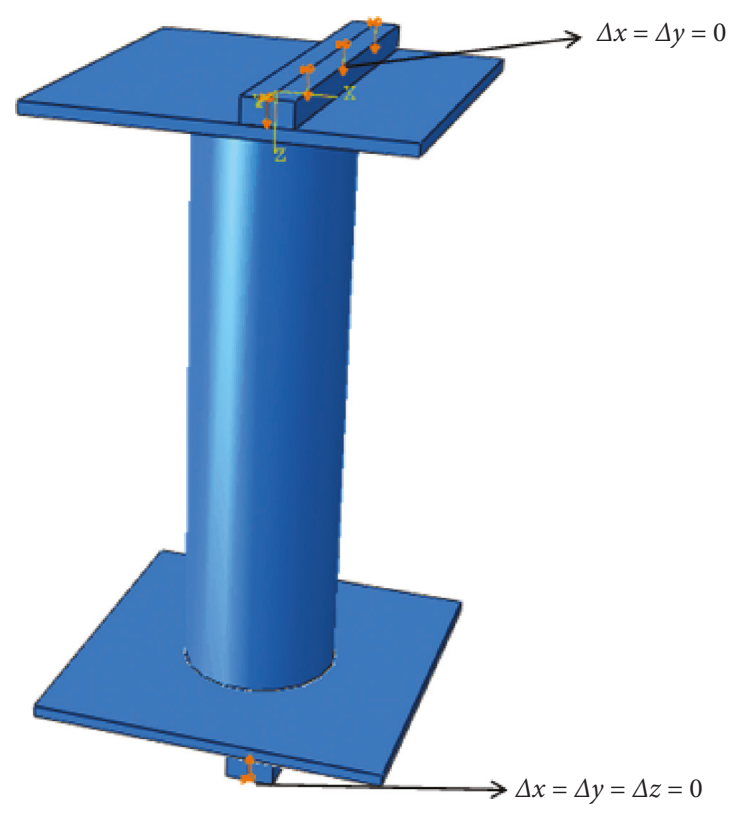

Figure 12: Load and boundary conditions.

interaction between the two surfaces of normal deformation, and the friction coefficient is 0.3 in this analysis. The contact type between loading plate and steel tube is shell-to-solidcoupling.

5.2.2. Loading Boundary Conditions. To effectively reflect the eccentric compression state, two loading plates are set on the bottom and top of the specimen, as shown in Figure 12. In order to prevent the deformation of two loading plates, Young's modulus of both loading plates is defined as $2.1 \times 10^{14} \mathrm{MPa}$ and Poisson's ratio is set as 0.3 . The degree of freedom at the bottom of specimen is fully constrained in rotations and translation, while the top of column is permitted to move in the $Z$ direction. A loading line is set on the top loading plate, and the displacement-controlled load is applied in the $Z$ direction.

5.2.3. Analysis Steps and Solid Elements. The incremental iteration method is adopted in this analysis to control time increment. The initial increment, minimum increment, and maximum increment are set as $0.001,1 \mathrm{E}-006$, and 10, respectively. S4R (four-node-reduced integral format shell elements element) and C3D8R (eight-node solid elements with three translation degrees of freedom) are adopted to mesh the outer steel tube and core RSC, respectively. The sensitivity study shows that the outer steel tube and core RSC can be meshed with $3 \mathrm{~mm}$ element size, and the finite element model and mesh division of each element are shown in Figure 13.

5.2.4. Evaluation of FE Model and Parametric Studies. The measured test data of bearing capacity and deflection of the RSCFCST column under eccentric compression are compared with the predicted values of the FE model, as shown in Table 3. $N_{\mathrm{u}}$ and $\Delta_{\mathrm{u}}$ stand for the measured ultimate load and deflection of specimen, respectively; $N_{f}$ is the predicted value of the ultimate load, and $\Delta_{\mathrm{f}}$ illustrates the predicted value of deflection. The predicted values of the FE model are in good agreement with the test data. The average values of $N_{\mathrm{f}} / N_{\mathrm{u}}$ and $\Delta_{\mathrm{f}} / \Delta_{\mathrm{u}}$ are $97.4 \%$ and $96 \%$, and their mean square errors are 0.042 and 0.037 , respectively.

The studied parameters including the yield strength of the steel $\left(f_{\mathrm{y}}\right)$, steel ratio $(\alpha)$, diameter-thickness ratio of the steel tube $(D / t)$, replacement ratio of RCA $(\gamma)$, strength grade of concrete, eccentricity ratio $(e / r)$, and length-diameter ratio $(L / D)$ of RSCFCST columns are considered. The detailed parameter values are listed in Table 4 . To evaluate the proposed model, the length-diameter ratio $(L / D)$ and eccentricity ratio $(e / r)$ are investigated comprehensively in this study. Meanwhile, other parameters are studied by fixing a specific value, as shown in Table 5. In addition, 14 combinations of $\gamma, f_{\mathrm{y}}, \alpha$, and $D / t$ and strength grade of concrete are created to run with each of 3 values for $e / r$ and $L / D$. A total of $14 \times 3 \times 3=126$ FE models are established.

\section{Evaluation of the Proposed Model}

In order to verify the accuracy of the effective stiffness calculation equation of RSCFCST columns under eccentric compression, the deflection values predicted by the proposed equation and test data in this study are compared in Table 6. The average ratio of the predicted value of the deflection by the proposed model to test data is 1.022 , and the mean square error is 0.123 . The results obtained from the proposed model are very close to the test data.

In addition, twelve recycled concrete-filled circular steel tubular columns under eccentric compression [49] are collected to further verify the applicability of the proposed equation for estimating the effective stiffness. As shown in Table 7 , the average ratio of the predicted value of the 


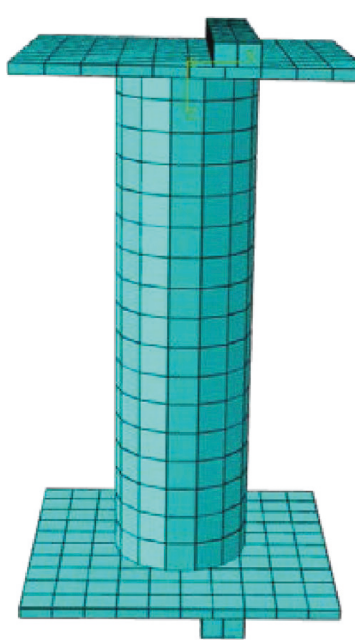

(a)

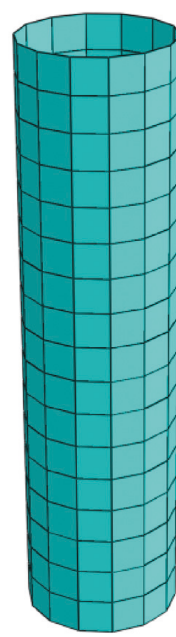

(b)

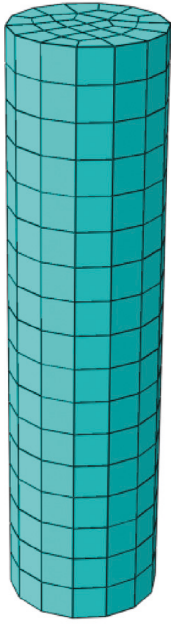

(c)

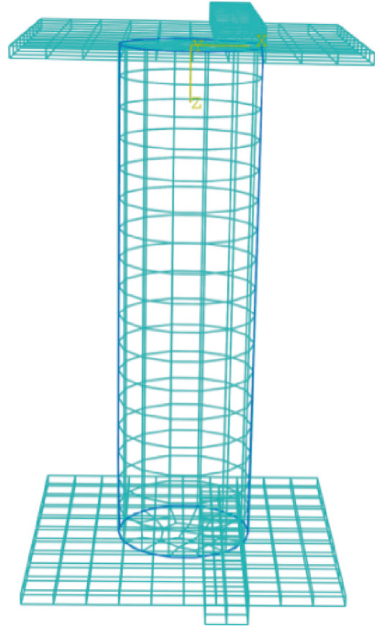

(d)

FIGURE 13: Typical FE model for the RSCFCST column: (a) integral model; (b) steel tube; (c) RSC; (d) wire frame of the integral model.

TABle 3: Comparison of FE prediction results and test data of specimen.

\begin{tabular}{|c|c|c|c|c|c|c|}
\hline Specimen & $\Delta_{\mathrm{f}}(\mathrm{mm})$ & $\Delta_{\mathrm{u}}(\mathrm{mm})$ & $N_{\mathrm{f}}(\mathrm{kN})$ & $N_{\mathrm{u}}(\mathrm{kN})$ & $N_{\mathrm{f}} / N_{\mathrm{u}}$ & $\Delta_{\mathrm{f}} / \Delta_{\mathrm{u}}$ \\
\hline RSCSE-1 & 4.72 & 5.02 & 807 & 819 & 0.99 & 0.94 \\
\hline RSCSE-2 & 5.88 & 6.02 & 598 & 603 & 0.99 & 0.98 \\
\hline RSCSE-3 & 6.02 & 6.18 & 450 & 512 & 0.88 & 0.97 \\
\hline RSCSE-4 & 5.29 & 5.54 & 766 & 776 & 0.99 & 0.95 \\
\hline RSCSE-5 & 6.46 & 6.76 & 569 & 557 & 1.02 & 0.96 \\
\hline RSCSE-6 & 6.45 & 6.92 & 433 & 457 & 0.95 & 0.93 \\
\hline RSCSE-7 & 5.95 & 6.39 & 759 & 761 & 1.00 & 0.93 \\
\hline RSCSE-8 & 6.62 & 7.02 & 557 & 552 & 1.01 & 0.94 \\
\hline RSCSE-9 & 6.71 & 7.04 & 425 & 441 & 0.96 & 0.95 \\
\hline RSCSE-10 & 7.02 & 7.26 & 856 & 893 & 0.96 & 0.97 \\
\hline RSCSE-11 & 9.36 & 9.97 & 636 & 670 & 0.95 & 0.94 \\
\hline RSCSE-12 & 9.28 & 10.03 & 478 & 504 & 0.95 & 0.93 \\
\hline RSCSE-13 & 6.39 & 6.02 & 921 & 898 & 1.03 & 1.06 \\
\hline RSCSE-14 & 6.36 & 6.26 & 691 & 672 & 1.03 & 1.02 \\
\hline RSCSE-15 & 6.21 & 6.67 & 539 & 585 & 0.92 & 0.93 \\
\hline Average value & - & - & - & - & 0.974 & 0.960 \\
\hline Mean square error & - & - & - & - & 0.042 & 0.037 \\
\hline
\end{tabular}

Note. $N_{\mathrm{f}}$ represents the predicted value of the ultimate load; $\Delta_{\mathrm{f}}$ denotes the predicted value of deflection.

TABLE 4: Values of studied parameters.

\begin{tabular}{lcc}
\hline Parameter & Values & Fixed values \\
\hline Yield strength of the steel $\left(f_{\mathrm{y}}\right)(\mathrm{MPa})$ & $235,345,390,420$ & 235 \\
Steel ratio $(\alpha)$ & $0.05,0.1,0.15,0.20$ & 0.1 \\
Diameter-thickness ratio of the steel tube $(D / t)$ & $30,38.6,50,70$ & 38.6 \\
Replacement ratio of RCA $(\gamma)$ & $0,50 \%, 100 \%$ & $100 \%$ \\
Strength grade of concrete & $\mathrm{C} 30, \mathrm{C} 50, \mathrm{C} 60$ & $\mathrm{C} 50$ \\
Eccentricity ratio $(e / r)$ & $0.3,0.6,0.9$ & - \\
Length-diameter ratio $(L / D)$ & $3.57,7.14,10.71$ & - \\
\hline
\end{tabular}

TABle 5: Combinations of $f_{\mathrm{y}}, \alpha, D / t, \gamma$, and strength grade of concrete.

\begin{tabular}{|c|c|c|c|c|c|c|c|c|c|c|c|c|c|c|}
\hline Parameter & Fixed values & & $f_{\mathrm{y}}$ & & & $\alpha$ & & & $D / t$ & & r & & $\begin{array}{l}\text { Stre } \\
\text { gra } \\
\text { con }\end{array}$ & $\begin{array}{l}\text { ngth } \\
\text { le of } \\
\text { rete }\end{array}$ \\
\hline Yield strength of the steel $(\mathrm{MPa})$ & 235 & 345 & 390 & 420 & 235 & 235 & & 235 & 235 & 235 & 235 & 235 & 235 & 235 \\
\hline & & 0.10 & 0.10 & 0.10 & 0.05 & 0.15 & 0.20 & 0.10 & 0.10 & 0.10 & 0.10 & 0.10 & 0.10 & 0.10 \\
\hline Diameter-thickness ratio & 38.6 & 38.6 & 38.6 & 38.6 & 38.6 & 38.6 & 38.6 & 30 & 50 & 70 & 38.6 & 38.6 & 38.6 & 38.6 \\
\hline Replacement ratio of RCA (\%) & 50 & 50 & 50 & 50 & 50 & 50 & 50 & 50 & 50 & 50 & 0 & 100 & 50 & 50 \\
\hline Strength grade of concrete & C50 & C50 & C50 & C50 & $\mathrm{C} 50$ & C50 & C50 & C50 & C50 & C50 & C50 & C50 & C30 & $\mathrm{C} 60$ \\
\hline
\end{tabular}


TABLE 6: Comparisons of the deflection values predicted by the proposed equation and test data of this study.

\begin{tabular}{lccc}
\hline Specimen ID & $\begin{array}{c}\text { Proposed model } \\
\Delta(\mathrm{mm})\end{array}$ & Test data $\Delta_{\mathrm{u}}(\mathrm{mm})$ & $\Delta / \Delta_{\mathrm{u}}$ \\
\hline RSCSE-1 & 5.27 & 5.02 & 1.05 \\
RSCSE-2 & 7.14 & 6.02 & 1.18 \\
RSCSE-3 & 7.32 & 6.18 & 1.18 \\
RSCSE-4 & 4.98 & 5.54 & 0.90 \\
RSCSE-5 & 6.57 & 6.76 & 0.97 \\
RSCSE-6 & 7.74 & 6.92 & 1.11 \\
RSCSE-7 & 5.11 & 6.39 & 0.80 \\
RSCSE-8 & 6.82 & 7.02 & 0.98 \\
RSCSE-9 & 7.78 & 7.04 & 1.10 \\
RSCSE-10 & 6.76 & 7.26 & 0.93 \\
RSCSE-11 & 8.21 & 9.97 & 0.83 \\
RSCSE-12 & 8.41 & 10.03 & 0.84 \\
RSCSE-13 & 5.62 & 6.02 & 0.94 \\
RSCSE-14 & 6.72 & 6.26 & 1.07 \\
RSCSE-15 & 7.68 & 6.67 & 1.15 \\
RSCSE-16 & 9.12 & 7.77 & 1.17 \\
RSCSE-17 & 11.31 & 10.59 & 1.06 \\
RSCSE-18 & 13.21 & 11.01 & 1.19 \\
RSCSE-19 & 11.40 & 12.51 & 0.92 \\
RSCSE-20 & 13.76 & 13.75 & 1.00 \\
RSCSE-21 & 15.48 & 14.16 & 1.09 \\
Mean square error & - & - & 0.123 \\
Average value & - & - & 1.022 \\
\hline
\end{tabular}

TABLe 7: Comparisons of the deflection values predicted by the proposed equation and test data of the reference.

\begin{tabular}{lccc}
\hline Specimen ID & $\begin{array}{c}\text { Proposed model } \\
\Delta(\mathrm{mm})\end{array}$ & Test data $\Delta_{\mathrm{u}}(\mathrm{mm})$ & $\Delta / \Delta_{\mathrm{u}}$ \\
\hline CL12-8-100-20 & 5.156 & 5.064 & 1.01 \\
CL12-8-100-40 & 6.366 & 6.499 & 0.98 \\
CL32-8-100-20 & 14.783 & 13.794 & 1.07 \\
CL32-11-100-20 & 16.662 & 13.914 & 1.19 \\
CL32-14-100-20 & 14.000 & 16.277 & 0.86 \\
CL32-8-50-20 & 13.800 & 13.345 & 1.03 \\
CL32-8-0-20 & 12.572 & 12.711 & 0.99 \\
CL32-8-100-40 & 16.213 & 13.154 & 1.23 \\
CL32-8-50-40 & 16.225 & 12.176 & 1.31 \\
CL32-8-0-40 & 14.311 & 12.034 & 1.18 \\
CL48-8-100-20 & 22.210 & 18.409 & 1.20 \\
CL48-8-100-40 & 19.000 & 19.412 & 0.98 \\
Mean square error & - & - & 0.133 \\
Average value & - & - & 1.086 \\
\hline
\end{tabular}

Note. An example of the test specimen identification system is as follows: CL12-8-100-0, where CL accounts for a composite column with the aggregate, the digit number " 12 " is the length-diameter ratio $(k=4 L / D)$, the digit " 8 " defines the nominal ratio $\alpha$ of $8 \%$, the digit " 100 " represents the RCA replacement ratio of $100 \%$, and the last one " 0 " denotes eccentricity of load with $0 \mathrm{~mm}$.

deflection to test data of reference is 1.086 , and the mean square error is 0.133 . Moreover, the abovementioned $126 \mathrm{FE}$ models are also employed to evaluate the accuracy of the proposed equation for predicting the effective stiffness, and the overall performance of the proposed equation is depicted in Figure 14. Test data, FE analysis results, and deflections predicted by equation are compared in Figure 14. Obviously,

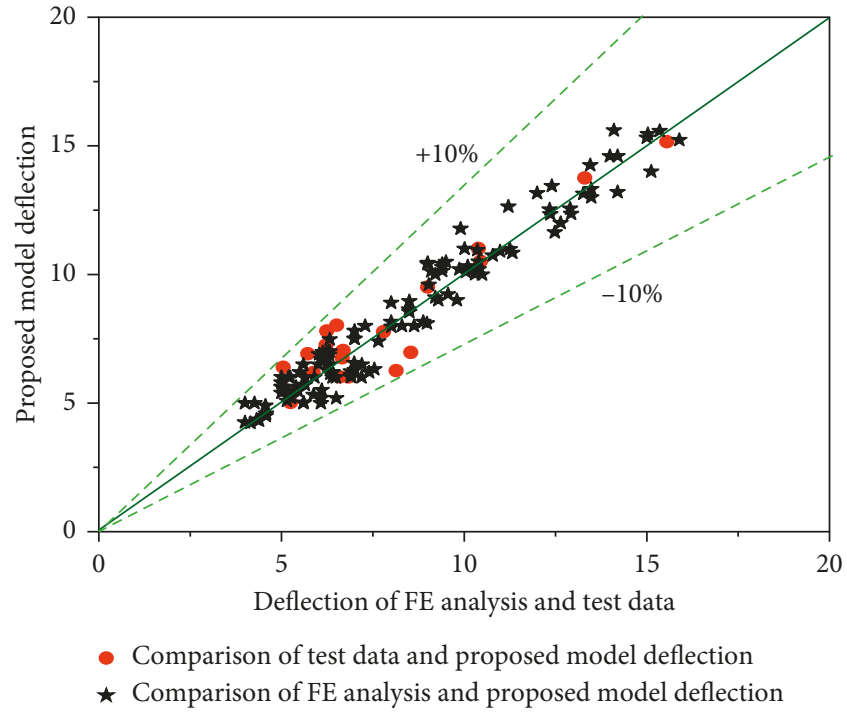

FIGURE 14: Overall performance of the proposed equation.

most cases are within $\pm 10 \%$ error lines. The predicted values from the proposed equation agree well with the test data and FE analysis. Therefore, the model proposed in this study can be adopted for evaluating the effective stiffness of the RSCFCST columns under eccentric compression.

\section{Conclusion}

Experimental research and $\mathrm{FE}$ analysis on mechanical performance of RSCFCST columns under eccentric compression are conducted in this study. The main conclusions are as follows:

(1) The RSCFCST short columns under eccentric compression exhibit drum-like bending failures, while the RSCFCST long columns under eccentric compression experience the global flexural buckling failure modes.

(2) With the replacement ratio of RCA, length-diameter ratio or eccentricity increases, the bearing capacity of RSCFCST columns under eccentric compression decreases. However, the bearing capacity of specimen increases as the strength grade of concrete increases.

(3) The stiffness of the RSCFCST columns under eccentric compression gradually increases as the strength grade of concrete increases, while the eccentricity had an adverse effect on stiffness of specimen. With the increase of load, the increase of the length-diameter ratio would accelerate the stiffness degradation of specimen. The effect of the replacement ratio of RCA on stiffness of specimen in the elastic stage is not obvious.

(4) The stress-strain curves are linear in the elastic stage. As load increases, the stress-strain curves deviate from linearity, and the strain growth rate increases as the replacement ratio of RCA, length-diameter ratio, 
or eccentricity increases, while the strain growth rate decreases as the strength grade of concrete increases.

(5) A validated FE model is employed to conduct parametric studies to widen the available test results. An analytical model for predicting the effective stiffness of the RSCFCST columns under eccentric compression is proposed based on the moment magnifier method, and verification of this analytical model is performed using the test data and FE analysis results.

\section{Data Availability}

The data used to support the findings of this study are included within the article. Reference test data in Table 7 can be obtained via https://www.sciencedirect.com/science/ article/pii/S0141029616307271.

\section{Conflicts of Interest}

The authors declare that they have no conflicts of interest.

\section{Acknowledgments}

This work was supported by the National Natural Science Foundation of China (nos. 51578001, 51608003, 51878002, and 51008001), Department of Education, Anhui Province (no. KJ2015ZD10), Key Research and Development Plan of Anhui Province (no. 1704a0802131), and Outstanding Young Talent Support Program of Anhui Province (no. gxyqZD2016072).

\section{References}

[1] M. D. R. Merino, P. I. Gracia, and I. S. W. Azevedo, "Sustainable construction: construction and demolition waste reconsidered," Waste Management \& Research, vol. 28, no. 2, pp. 118-129, 2010.

[2] L. Zheng, H. Wu, H. Zhang et al., "Characterizing the generation and flows of construction and demolition waste in China," Construction and Building Materials, vol. 136, pp. 405-413, 2017.

[3] A. Akhtar and A. K. Sarmah, "Construction and demolition waste generation and properties of recycled aggregate concrete: a global perspective," Journal of Cleaner Production, vol. 186, pp. 262-281, 2018.

[4] P. D. Vries, "Concrete re-cycled. Crushed concrete as aggregate," Concrete, vol. 27, pp. 9-13, 1919.

[5] N. Kisku, H. Joshi, M. Ansari, S. K. Panda, S. Nayak, and S. C. Dutta, "A critical review and assessment for usage of recycled aggregate as sustainable construction material," Construction and Building Materials, vol. 131, pp. 721-740, 2016.

[6] S. Laserna and J. Montero, "Influence of natural aggregates typology on recycled concrete strength properties," Construction and Building Materials, vol. 115, no. 7, pp. 78-86, 2016.

[7] J. Thomas, N. N. Thaickavil, and P. M. Wilson, "Strength and durability of concrete containing recycled concrete aggregates," Journal of Building Engineering, vol. 19, pp. 349-365, 2018.
[8] F. U. A. Shaikh, "Mechanical and durability properties of fly ash geopolymer concrete containing recycled coarse aggregates," International Journal of Sustainable Built Environment, vol. 5, no. 2, pp. 277-287, 2016.

[9] C. M. Zhu and T. Li, "Mechanical properties of waste concrete-participated recycled concrete," Journal of South China University of Technology, vol. 42, no. 2, pp. 50-56, 2014.

[10] V. W. Y. Tam, C. M. Tam, and K. N. Le, "Removal of cement mortar remains from recycled aggregate using pre-soaking approaches," Resources, Conservation and Recycling, vol. 50, no. 1, pp. 82-101, 2007.

[11] K. K. Choi and Y. Xiao, "Analytical studies of concrete-filled circular steel tubes under axial compression," Journal of Structural Engineering, vol. 136, no. 5, pp. 565-573, 2010.

[12] K. Chung, S. Park, and S. Choi, "Fire resistance of concrete filled square steel tube columns subjected to eccentric axial load," International Journal of Steel Structures, vol. 9, no. 1, pp. 69-76, 2009.

[13] Y. Wen, L. Guan, and B. F. Zhang, "Contrast experiments on seismic performances of different concrete-filled steel tube beam joints," Journal of Shenyang Jianzhu University (Natural Science), vol. 5, no. 31, pp. 821-828, 2015.

[14] J. F. Wang, Z. H. Yu, and Q. H. Shen, "Torsional behavior numerical analysis and torsion bearing capacity calculation of circular-end elliptical concrete-filled steel tube," Journal of Architecture and Civil Engineering, vol. 3, pp. 1673-2049, 2018.

[15] E. Ellobody and B. Young, "Design and behaviour of concretefilled cold-formed stainless steel tube columns," Engineering structures, vol. 28, no. 5, pp. 716-728, 2006.

[16] E. K. Mohanraj, S. Kandasamy, and R. Malathy, "Behaviour of steel tubular stub and slender columns filled with concrete using recycled aggregates," Journal of South African Institution of Civil Engineering, vol. 53, no. 2, pp. 31-38, 2011.

[17] Y.-F. Yang and L.-H. Han, "Experimental behaviour of recycled aggregate concrete filled steel tubular columns," Journal of Constructional Steel Research, vol. 62, no. 12, pp. 1310-1324, 2006.

[18] Z. P. Chen, Q. L. Li, X. G. Zhang, J. Y. Xue, and B. C. Chen, "Mechanical behavior and bearing capacity calculation of recycled aggregate concrete-filled circular steel tube columns under eccentric loading," China Civil Engineering Journal, vol. 45, no. 10, 2012.

[19] Y.-C. Tang, L.-J. Li, W.-X. Feng, F. Liu, and B. Liao, "Seismic performance of recycled aggregate concrete-filled steel tube columns," Journal of Constructional Steel Research, vol. 133, pp. 112-124, 2017.

[20] J.-J. Xu, Z.-P. Chen, J.-Y. Xue, Y.-L. Chen, and J.-T. Zhang, "Simulation of seismic behavior of square recycled aggregate concrete-filled steel tubular columns," Construction and Building Materials, vol. 149, pp. 553-566, 2017.

[21] Y. Geng, Y. Wang, and J. Chen, "Time-dependent behaviour of steel tubular columns filled with recycled coarse aggregate concrete," Journal of Constructional Steel Research, vol. 122, pp. 455-468, 2016.

[22] M. Mahgub, A. Ashour, D. Lam, and X. Dai, "Tests of selfcompacting concrete filled elliptical steel tube columns," ThinWalled Structures, vol. 110, no. 1, pp. 27-34, 2017.

[23] G. Muciaccia, F. Giussani, G. Rosati, and F. Mola, "Response of self-compacting concrete filled tubes under eccentric compression," Journal of Constructional Steel Research, vol. 67, no. 5, pp. 904-916, 2011.

[24] S. Elzbieta and W. Piot, "Bonding between steel and self compacting concrete in composite columns," Stahlbau, vol. 81, no. 8, pp. 616-620, 2012. 
[25] F. X. Ding and Z. W. Yu, "Pure bending properties of selfcompacting concrete filled circular steel tube," Journal of Traffic \& Transportation Engineering, vol. 6, no. 1, pp. 63-67, 2006.

[26] J. C. Dotreppe, T. B. Chu, and J. M. Franssen, "Steel hollow columns filled with self-compacting concrete under fire conditions," in Proceedings of the 3rd International FIB Congress and Exhibition, Incorporating the PCI Annual Convention and Bridge Conference, Washington, DC, USA, May 2010.

[27] GB/T228.1-2010, "Metallic materials-tensile testing-part 1: method of test at room temperature (ISO 6892-1:2009, MOD)," 2010.

[28] JGJ 52-2006, "Standard for technical requirements and test method of sand and crushed stone (or gravel) for ordinary concrete," 2006.

[29] JGJ/T283-2012, "Technical specification for application of self-compacting concrete," 2012.

[30] J. L. Bonet, M. L. Romero, and P. F. Miguel, "Effective flexural stiffness of slender reinforced concrete columns under axial forces and biaxial bending," Engineering Structures, vol. 33, no. 3, pp. 881-893, 2011.

[31] B. Yan, X. Zhou, and J. Liu, "Behavior of circular tubed steelreinforced-concrete slender columns under eccentric compression," Journal of Constructional Steel Research, vol. 155, pp. 342-354, 2019.

[32] Y. Zheng and Z. Tao, "Compressive strength and stiffness of concrete-filled double-tube columns," Thin-Walled Structures, vol. 134, pp. 174-188, 2019.

[33] H. Ma, J. Dong, G. Hu, and Y. Liu, "Axial compression performance of composite short columns composed of RACfilled square steel tube and profile steel," Journal of Constructional Steel Research, vol. 153, pp. 416-430, 2019.

[34] M. Ahmadi, S. Farzin, A. Hassani, and M. Motamedi, "Mechanical properties of the concrete containing recycled fibers and aggregates," Construction and Building Materials, vol. 144, pp. 392-398, 2017.

[35] Y. Huang, X. He, Q. Wang, and Y. Sun, "Mechanical properties of sea sand recycled aggregate concrete under axial compression," Construction and Building Materials, vol. 175, pp. 55-63, 2018.

[36] F. Deng, Y. He, S. Zhou, Y. Yu, H. Cheng, and X. Wu, "Compressive strength prediction of recycled concrete based on deep learning," Construction and Building Materials, vol. 175, pp. 562-569, 2018.

[37] M. G. Beltran, A. Barbudo, F. Agrela, A. P. Galvín, and J. R. Jiménez, "Effect of cement addition on the properties of recycled concretes to reach control concretes strengths," Journal of Cleaner Production, vol. 79, pp. 124-133, 2014.

[38] J. Xiao, J. Li, and C. Zhang, "Mechanical properties of recycled aggregate concrete under uniaxial loading," Cement and Concrete Research, vol. 35, no. 6, pp. 1187-1194, 2005.

[39] Eurocode 4, Design of Composite Steel and Concrete Structures. Part 1.1: General Rules and Rules for Buildings, European Committee for Standardization, Brussels, Belgium, 2004.

[40] ACI 318-14, Building Code Requirements for Structural Concrete and Commentary, American Concrete Institute, Farmington Hills, MI, USA, 2014.

[41] CECS28:1990, Specification for Design and Construction of Concrete Filled Steel Tubular Structures, China Planning Press, Beijing, China, 1990.

[42] H. Karlson and S. Abaqus, Version 6.4: Theory Manual, Users' Manual, Verification Manual and Example Problems Manual, Hibbitt, Karlson, Sorenson Inc., Providence, RI, USA, 2003.
[43] S. T. Zhong, The Concrete-Filled Steel Tubular Structures, Tsinghua University Press, Beijing, China, 3rd edition, 2003.

[44] J. Y. Xue, Steel-Concrete Composite Structures, vol. 8, Huazhong University of Science and Technology Press, Wuhan, China, 2007.

[45] GB50936-2014, Technical code for concrete filled steel tubular structures, Standards Press of China, Beijing, China, 2014.

[46] J. Z. Xiao, "Experimental investigation on complete stressstrain curve of recycled concrete under uniaxial loading," Journal of Tongji University (natural science), vol. 35, no. 11, pp. 1445-1449, 2007.

[47] L. H. Han, Concrete Filled Steel Tubular Structure, Science Press, Beijing, China, 2000.

[48] M. F. Hassanein, O. F. Kharoob, and L. Gardner, "Behaviour and design of square concrete-filled double skin tubular columns with inner circular tubes," Engineering Structures, vol. 100, pp. 410-424, 2015.

[49] J. Chen, Y. Wang, C. W. Roeder, and J. Ma, "Behavior of normal-strength recycled aggregate concrete filled steel tubes under combined loading," Engineering Structures, vol. 130, pp. 23-40, 2017. 


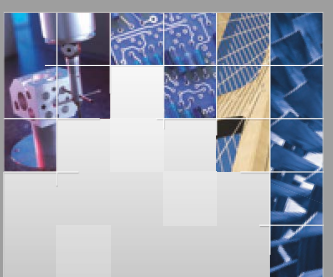

\section{Enfincering}
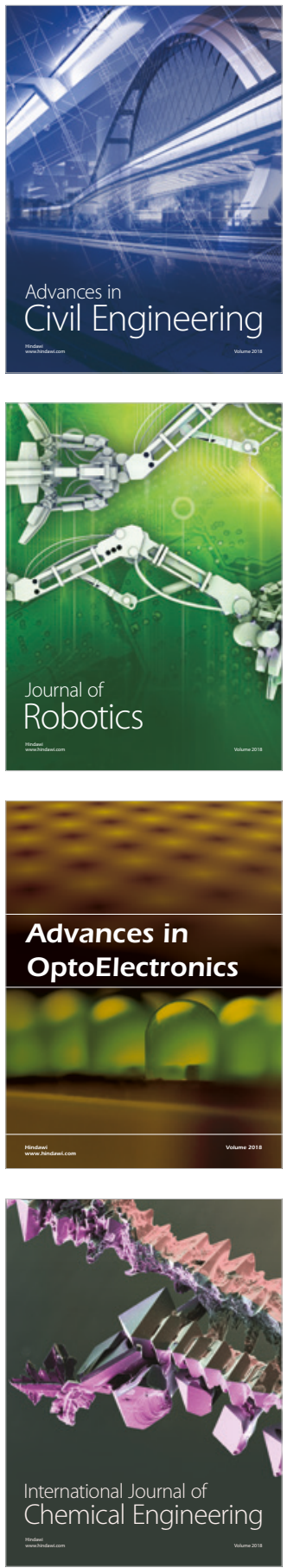

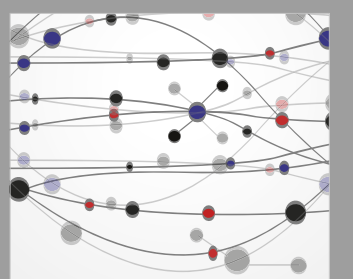

\section{Rotating \\ Machinery}

The Scientific World Journal

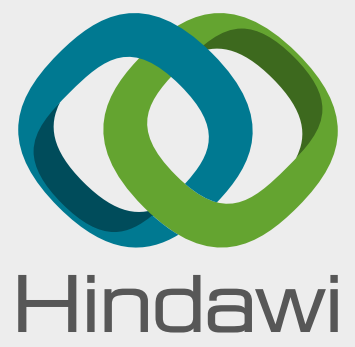

Submit your manuscripts at

www.hindawi.com
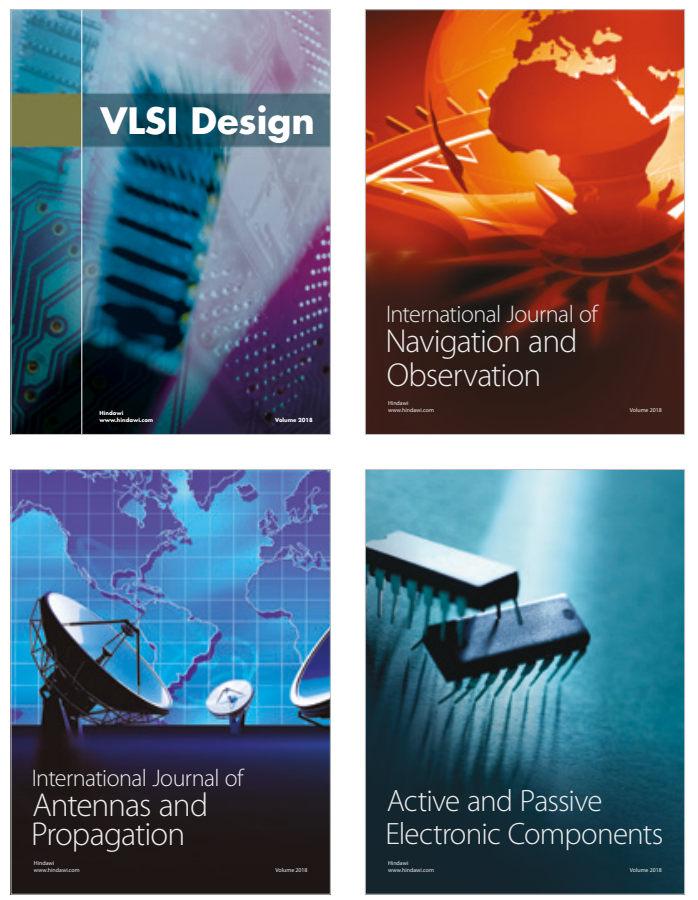
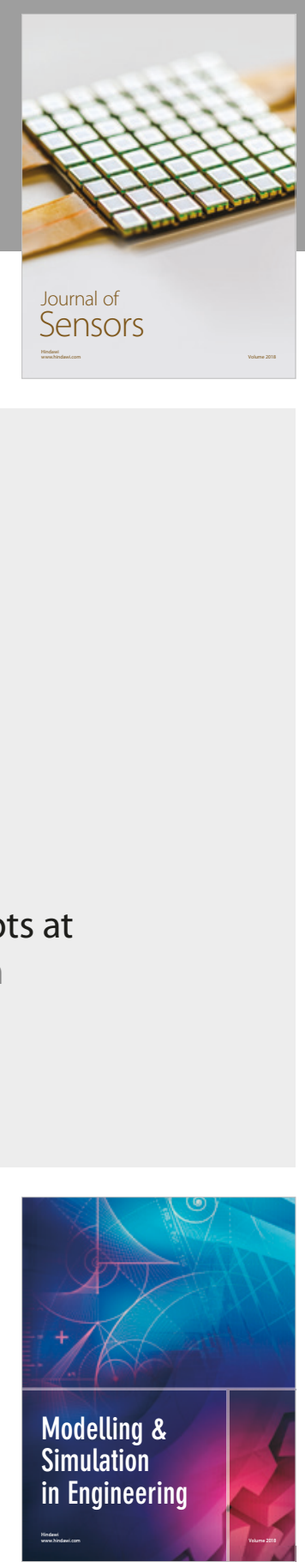

\section{Advances \\ Multimedia}
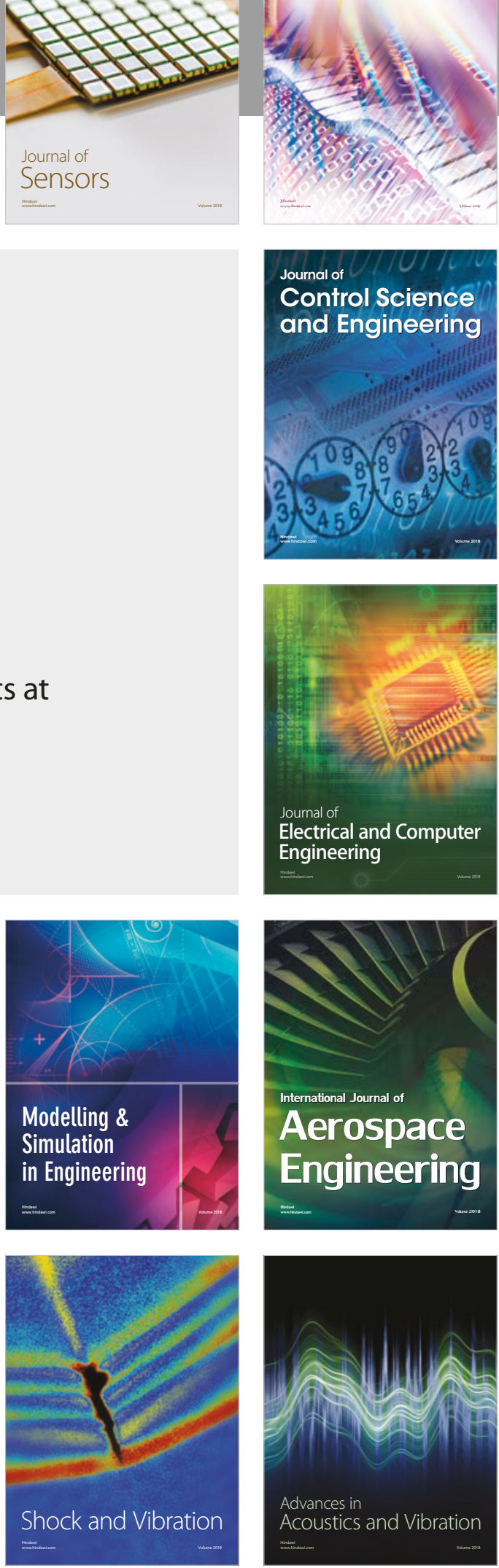